Aquaculture

April 2017, Volume 472, Pages 156-177

http://dx.doi.org/10.1016/i.aquaculture.2016.05.042

http://archimer.ifremer.fr/doc/00341/45172/

(c) 2016 Elsevier B.V. All rights reserved.

\title{
Cryobanking of aquatic species
}

Martínez-Páramo Sonia ${ }^{1}$, Horváth Ákos ${ }^{2}$, Labbé Catherine ${ }^{3}$, Zhang Tiantian ${ }^{4}$, Robles Vanesa ${ }^{5}$, Herráez Paz ${ }^{6}$, Suquet Marc ${ }^{7}$, Adams Serean ${ }^{8}$, Viveiros Ana ${ }^{9}$, Tiersch Terrence R. ${ }^{10}$, Cabrita Elsa ${ }^{1,}$

${ }^{1}$ CCMAR-Centre of Marine Sciences, University of Algarve, Campus Gambelas, 8005-139 Faro,

Portugal

${ }^{2}$ Department of Aquaculture, Szent István University, H-2100, Gödöllö, Hungary

${ }^{3}$ INRA, Fish Physiology and Genomics, Campus de Beaulieu, F-35000 Rennes, France

${ }^{4}$ Graduate School, Bournemouth University, Poole House, Talbot Campus, Fern Barrow Poole Dorset, BH12 5BB, United Kingdom

${ }^{5}$ IEO, Spanish Oceanographic Institute, Santander Oceanographic Centre, El Bocal, Barrio Corbanera $\mathrm{s} / \mathrm{n}$ Bocal, 39012 Monte Santander, Spain

${ }^{6}$ Department of Molecular Biology and INDEGSAL, University of León, 24071, León, Spain

7 IFREMER, PFOM Dept, Stn Expt Argenton, UMR 6539, Argenton, France

${ }^{8}$ Cawthron Institute, Private Bag 2, Nelson, New Zealand 7042. AgResearch, Private Bag 3123, Ruakura, Hamilton 3240, New Zealand

${ }^{9}$ Department of Animal Sciences, Federal University of Lavras, UFLA, MG, Brazil

${ }^{10}$ Aquatic Germplasm and Genetic Resources Center, School of Renewable Natural Resources, Louisiana State University Agricultural Center, Baton Rouge, Louisiana, USA

*Corresponding author : Elsa Cabrita, email address : ecabrita@ualg.pt

\begin{abstract}
:
This review is focused on the applications of genome cryobanking of aquatic species including freshwater and marine fish, as well as invertebrates. It also reviews the latest advances in cryobanking of model species, widely used by the scientific community worldwide, because of their applications in several fields. The state of the art of cryopreservation of different cellular types (sperm, oocytes, embryos, somatic cells and primordial germ cells or early spermatogonia) is discussed focusing on the advantages and disadvantages of each procedure according to different applications. A special review on the need of standardization of protocols has also been carried out. In summary, this comprehensive review provides information on the practical details of applications of genome cryobanking in a range of aquatic species worldwide, including the cryobanks established in Europe, USA, Brazil, Australia and New Zealand, the species and type of cells that constitute these banks and the utilization of the samples preserved.
\end{abstract}

\section{Statement of relevance}

This review compiles the last advances on germplasm cryobanking of freshwater and marine fish species and invertebrates, with high value for commercial aquaculture or conservation. It is reviewed the most promising cryopreservation protocols for different cell types, embryos and larvae that could be applied in programs for genetic improvement, broodstock management or conservation of stocks to 
guarantee culture production.

\section{Highlights}

- Germplasm cryobanking has huge potential in aquaculture and conservation programs Cryobanks established in Europe, USA, Brazil, New Zealand and Australia are reviewed Trends on standardization of cryopreservation procedures in aquatic species - Germinal cells, somatic cells and embryos: strength and pitfalls of cryopreservation

Keywords : Cryobanking, aquatic animals, fish gametes, germplasm 


\section{Introduction to germplasm cryobanking}

Germplasm cryobanking has important applications in reproductive practices in cultured marine and freshwater aquatic species by simplifying broodstock management. Its potential has also been evident in maintaining important strains of laboratory model fish species. Cryobanking has also been a valuable tool to preserve the genetic resources of a wide range of species and with the help of reproductive biotechnologies, such as germ cell xenotransplantation, it plays an important role in genetic selection programs, biodiversity preservation and assisted reproduction. According to the Red List of the International Union for Conservation of Nature and Natural Resources (IUCN, 2015), there are 5,161 threatened aquatic animal species in the world, including fishes, molluscs, crustaceans and corals, therefore, cryopreservation could be a secure method to preserve the genetic material of these species, providing the opportunity to preserve representative samples and further reconstruct the original strain, population or diversity. The management of these banks requires technical capacity in genetics, reproductive physiology, cryobiology and data administration. Cryopreservation protocols must be carefully designed for each species and each type of cells. This review will focus on the potential of cryobanking in aquatic animals, including freshwater and marine fish species as well as invertebrates.

\section{Fish sperm cryopreservation}

Since the first attempts to cryopreserve fish sperm, the potential application of this methodology to freshwater and marine species has attracted the attention of researchers. Freezing protocols have been developed for many different species around the world, the numeriouse studies have focused on species from temperate climates and with seasonal reproduction. Among them, salmonids and cyprinids, are by far the most 
extensively studied because of their high commercial value, either as food or for recreation purposes such as fishing. Research on fish germplasm cryobanking has been carried out on different cells types, including sperm, somatic cells, and more recently spermatogonia and primordial germ cells as well as fish oocytes and embryos. However, mainly due to their small size and relatively high resistance to chilling, spermatozoa present some advantages comparing to other cell types, resulting in sperm cryopreservation the most established technique in aquatic species.

\subsection{Cryopreservation of sperm from aquaculture species}

Extensive reviews, in some cases including detailed protocols for farmed species, have been published by different authors in recent years (Cabrita et al., 2008; Kopeika et al., 2007; Tiersch et al., 2007, 2011). Therefore, in this review we will focus on the research carried out in the last 5 years on commercial species.

\subsubsection{Freshwater species}

Most of the recent reports are still focused on salmonids, cyprinids and sturgeons

(Figure 1) but there is an increasing interest in designing cryopreservation protocols for species from tropical and subtropical areas (Maria et al., 2015; Viveiros and Godinho, 2009). Traditional empirical studies in a factorial experimental design testing a range of freezing rates, cryoprotectants or extenders are still conducted in order to develop cryopreservation protocols for species such as Atlantic salmon (Dziewulska et al., 2011), beluga sturgeon (Aramli et al., 2015), Siberian sturgeon (Judycka et al., 2015), perch (Bernáth et al., 2015) or tambaqui (Maria et al., 2015; Varela Junior et al., 2015). Nevertheless, the evaluation of sperm quality after freezing/thawing has evolved, allowing a better understanding of the mechanisms linking to the compromised quality 
during the cryopreservation process. The motility analysis is commonly performed using computerized systems. Flow cytometry is used to obtain reliable data about cell membrane or mitochondrial status, antioxidant status is evaluated using different methodologies, and chromatin integrity is also considered as an important checkpoint (reviewed by Cabrita et al., 2014). Moreover, proteome analysis contributes to deeper understanding in sperm physiology, revealing changes in proteins related to membrane traffick and organization, metabolism or signal transduction (Li et al., 2010,2013; Nynca et al., 2015a), providing valuable information on the nature of cryodamage (Figure 2). In addition, beyond fertilization rate, different studies have evaluated the long-term development of the progeny (Pérez-Cerezales et al., 2011; Viveiros et al., 2012).

The objective of reducing oxidative stress has been achieved by adding different compounds into the freezing extender. There are a number of identified natural and synthetic antioxidants which showed varying level of efficiency depending on the species, concentration or if they were combined with other compounds. Lahnsteiner and his colleagues (2011), tested 10 antioxidant mixtures containing catalase, superoxide dismutase, peroxidase, reduced glutathione, reduced methionine, oxidized glutathione and oxidized methionine and did not show a significant improve on sperm post-thaw quality in Salvelinus fontinalis and Oncorhynchus mykiss). However, different results were obtained in $O$. mykiss in an experiment in which post-thaw motility increased with 5 of the 11 tested antioxidants, but the fertility and hatching rates were not enhanced (Kutluyer et al., 2014). Better results were obtained with beluga sturgeon, where the addition of a synthetic phosphorous-containing phenol to modified Stein's medium doubled the fertility of thawed sperm (Osipova et al., 2014). An analysis of oxidative stress in carp sperm revealed that sperm dilution in extenders containing either dimethyl 
sulfoxide (DMSO) or ethylene glycol did not show any oxidative effects, whereas freezing promoted a significant oxidative damage, mainly with the use of DMSO as cryoprotectant (Li et al., 2010). Comparing changes in protein phosphorilation occurring during cryopreservation with the same cryoprotectants also revealed that the use of DMSO affected the biochemical profile of carp spermatozoa more seriously than other cryoprotectants (Li et al., 2013).

Progresses in carp sperm freezing include different modifications toconventional techniques and the addition of several compounds into the freezing media in order to increase cryoresistance. In these species, membrane protection has been improved using $1.5 \mathrm{mg}$ per $120 \times 10^{6}$ spermatozoa of cholesterol-loaded cyclodextrin, which promoted a significant increase in motility, viability and fertility (Yildiz et al., 2015). The addition of $20 \mathrm{mM}$ cysteine rendered higher motility, fertility and hatching rates and lower level of DNA damage (Öğretmen et al., 2015). Extender supplementation with a variety of compounds, including butylated hydroxytoluene (BHT) (Öğretmen and İnanan, 2014b), Turkish pine honey (Öğretmen and İnanan, 2014a) and propolis (Öğretmen et al., 2014) has been evaluated with variable results.

For salmonids, fertility rates similar to those obtained with control sperm were obtained with sperm to egg ratios as low as 50,000:1 for grayling (Horváth et al., 2015), 300,000:1 for brook and brown trout (Nynca et al., 2014, 2015b), 500,000:1 for huchen (Nynca et al., 2015c) and 600,000:1 for rainbow trout (Ciereszko et al., 2014). Vitrification is a rarely used technique in fish sperm but with promising aplications. Vitrification of sperm diluted in Cortland medium with 10\% DMSO, 2\% BSA, $0.13 \mathrm{M}$ sucrose and 50\% seminal plasma was reported as an option in Atlantic salmon cryopreservation (Figueroa et al., 2015). The authors reported good membrane integrity, motility and fertility and low DNA fragmentation rates under these conditions. 


\subsubsection{Marine Species}

Cryopreservation of sperm from most marine fish species is not as developed as for freshwater species, and most of the work conducted in the recent years has been done on freshwater species (Figure 3).

One of the reasons for the lack of research and application of cryopreservation technique at production level is the fact that the reproduction of most marine commercial species occurs naturally in the tank, where no artificial fertilization is required, thus reducing the need for gamete management techniques. There are of course exceptions, such as halibut (Hypoglossus hypoglossus) or turbot (Scophthalmus maximus), where important research on sperm cryopreservation has been carried out (Chereguini et al., 2003, Babiak et al., 2008). Most of the work conducted in new species is targeting conservation of stocks for guaranteeing culture production, genetic improvement programs and broodstock management. Successful cryopreservation of male gametes of marine species would contribute to the success of these programs. Despite great interest in optimising genetic resources or limiting risks associated with horizontal disease transmission, there has been limited reports on sperm cryopreservation of new species introduced in aquaculture industry. In flatfish species, successful cryopreservation of Atlantic halibut sperm was first reported by Bolla et al. (1987. Since then, several studies reported the improved the quality of cryopreserved sperm as well as the technology needed for applications in industry (Babiak et al., 2006a; Ding et al., 2011). The methods developed allow the storage of large amount of sperm produced by each male $(5-100 \mathrm{ml})$, maintaining a high fertilization capacity. This has increased the applicability of cryopreservation for commercial operators, and provided a useful tool for seedstock production and broodstock management (Ding et al., 2011, 2012), solving some of the problems of non- 
synchronization between both sexes at the end of spawning (females still have good eggs where males produce bad sperm quality with high viscosity) and allowing a reduction of manipulation of breeders for spawning (Babiak et al., 2006a; b). Protocols for other flatfish species were also recently developed, such as for Senegalese sole (Solea senegalensis) and summer flounder (Paralichthys dentatus). For Senegalese sole protocols were adapted from turbot (Rasines et al., 2013) and the work is still ongoing to improving the quality of post-thaw samples (Morais et al., 2014).

There are also protocols for new species being introduced in aquaculture in order to address the problems associated with overexploitation of existing fisheries resources. Commercial culture of snappers (Lutjanus genus) is increasing worldwide and cryopreservation of spermatozoa is a vital procedure for facilitating the controlled reproduction of fish, overcoming some of the problems associated with broodstock supply (Vuthiphandchai et al., 2009). Research has been conducted in this fish group in order to develop protocols for cryopreservation of sperm in several species of this genus (Gaitán-Espitia et al., 2013). Some snappers (Lutjanus analis) are also listed as vulnerable by the IUCN and have been cultured in experimental farms in the Caribbean, Colombia and Brazil and protocols for sperm cryopreservation are under development (Sanches et al., 2013).

Research has also been conducted for groupers in the recent years in Asian countries such as Korea, China, Taiwan, Vietnam, Philippines and Thailand showing the potential of cryopreservation of sperm from some species for production. Sperm cryopreservation would guarantee seed production since these species are protogynous hermaphrodites and size-selective fishing has significantly reduced male populations, making it extremely difficult to obtain wild male breeders for aquaculture. In the Mediterranean and in the Southeast Asian coast, the dusky grouper (Epinephelus marginatus) and the 
red-spotted grouper (Epinephelus akaara) are two endangered species (IUCN red list) and cryopreservation of sperm would guarantee the development of breeding strategies and restocking programs (Cabrita et al., 2009). Several studies were conducted on sperm cryopreservation of this group as a way to synchronize gamete availability between species. Studies on hybridization, favouring the cultivation of specific fish characteristics such as rapid growth (giant grouper, E. lanceolatus) or tolerance to crowding (orange-spotted grouper, E. coioides) (Kiriyakit et al., 2011) have been carried out.

Gadiforms form the basis of large, intensive fishing industries both in the Southern and Northern hemisphere, leading to over-exploitation of stocks in some areas with consequences in reduced catches (Groison et al., 2010). There is therefore a need for research in order to develop captive breeding of some of these species. The genus Merluccius has been shown to have potential interest to aquaculture worldwide and techniques such as cryopreservation can significantly contribute to its development. However, very limited studies have been conducted so far. There is a growing interest in farming of European hake, Merluccius merluccius and Merluccius australis (Chile). Thus, knowledge of sperm biology is of importance not only for broodstock management, but also for the development of sperm preservation techniques (Effer et al., 2013; Groison et al., 2010). Atlantic cod, Gadus morhua is another gadiform species where research on cryopreservation protocols has been developed. Presently, cod aquaculture production is primarily based on spawning from wild-caught stocks (Butts et al., 2010). Broodstock selection programs are currently underway for cod (http://www.genomecanada.ca), in combination with genomic technologies, will lead to the identification of cod with traits of commercial importance (Symonds and Bowman, 
2007). Cryopreservation of male gametes will be an important element in the creation of families for laboratory and hatchery production (Butts et al., 2010) in such programes. For all these fish groups, the successful cryopreservation protocols included a number of cryoprotectants but for most of the species, $10 \%$ DMSO produced the best results in terms of motility and fertility rates. In grouper species, $15 \%$ trehalose (giant grouper, Kiriyakit et al., 2011) and 10\% glycerol (longtooth grouper, Lim and Le, 2013) also provided good results. The incorporation of other compounds which interact with plasma membrane such as BSA and cholesterol yielded high fertility rates (Cabrita et al., 2009; He et al., 2011). For flatfish sperm, DMSO has been producing the best results in terms of post-thaw quality, although $15 \%$ propylene glycol produced similar fertility rates in summer flounder, Paralichthys dentatus (93\%, Liu et al., 2015). Research on sperm cryopreservation has been conducted at several levels, from application in laboratories to commercial production, incentivising biotechnological companies to invest in studies of some of these species (www.cryogenetics.com). There are other species where research on sperm cryopreservation has been more developed in terms of post-thaw quality control. This is the case in most of the marine species with high production demand in Europe, such as gilthead seabream (Sparus aurata) and European seabass (Dicentrarchus labrax). Studies in these two species reported specific damage to sperm due to cryopreservation. In European seabass, from the first reports in the late nineties by Fauvel et al. (1998), several improvements were made to the protocols using different extender solutions (Fauvel et al., 2012), successfully incorporating antioxidants such as taurine, hypotaurine and $\alpha$-tocopherol in the freezing media (Martínez-Páramo et al., 2012, 2013). Sperm quality was assessed by determining damage associated with cell metabolism, peroxidation events, DNA fragmentation and changes in protein profiles (Martínez-Páramo et al., 2013; Zilli and 
Vilella, 2012). In the same line of research, specific regions in gilthead seabream sperm genome were also studied after cryopreservation, as well as the presence of specific mRNAs associated with gamete quality and fertilization events (Cartón-García et al., 2013; Guerra et al., 2013). Specific genome regions were found to be more vulnerable to cryodamage. Consequently, researchers focused on the possible effects of sperm cryodamage on fertilization and future progeny and demonstrated that the protocol for gilthead seabream sperm cryopreservation developed and used by several authors (Beirão et al., 2011; Cabrita et al., 2005; Fabbrocini et al., 2000) does not affect mRNA levels nor it induces telomere shortening. This fact could be attributed in part to the efficient preservation of DNA integrity (\% DNAt lower than $2.47 \%$ ), avoiding any serious effect on fertilization or even on the offspring (Cartón-García et al., 2013; Guerra et al., 2013).

\section{2. Cryopreservation of fish sperm for conservation and restocking programs}

An important purpose of developing fish sperm cryopreservation protocols is their application in restocking and conservation programs. Conservation-oriented methods have been developed for various taxa, including acipenseriform fish (Ciereszko et al., 2006; Horvath et al., 2005), salmonids (Martínez-Páramo et al., 2009b; Nynca et al., 2015c; Sarvi et al., 2006), cyprinids (Basavaraja and Hegde, 2004; Tiersch et al., 2004) and other fish species (Asturiano et al., 2003; Maria et al., 2006; Orfão et al., 2011). In addition, studies have been carried out to assess the effect of cryopreservation on the genetic diversity of some species (Martínez-Páramo et al., 2009b; Van Der Walt et al., 1993). All these provide an important background for the application of developed methods in conservation actions. 
There has been very limited information on the actual application of succefful cryopreservation protocols in aquaculture practice or conservation programs. Some studies explore the possibility of application in conservation actions such as in the case of North-American salmonids (Cloud et al., 1990), but do not describe application in details. In aquaculture practice, cryopreserved sperm banks have been developed for the common carp in Hungary (Horváth, 2007) and in Israel (Lubzens et al., 1997). The United States Department of Agriculture (USDA) runs the National Animal Germplasm Program (NAGP, http://ars.usda.gov/research/projects/projects.htm?accn_no=423549) which includes conservation of cryopreserved samples from several fish species. A good example of combination of aquaculture and species conservation application is the cryopreserved gene bank of Atlantic salmon (Salmo salar) in Norway which contained sperm from 6,500 individuals from 169 populations in 2007 (O'Reilly and Doyle, 2007). The importance of cryopreserved sperm banks in countries with a diverse freshwater fish fauna such as Brazil has also been recognized (Viveiros and Godinho, 2009) and a cryopreserved germplasm repository of the species tambaqui (Colossoma macropomum) and cachara (Pseudoplatystoma reticulatum) has been created (Streit Jr. et al., 2013). Regarding direct conservation programs, cryopreservation has successfully been applied to the restocking program of the Adriatic lineage of the grayling (Thymallus thymallus) in Slovenia because its gene pool has been compromised by hybridization with introduced non-native stocks (Horváth et al., 2012).

The lack of information on the application of sperm cryopreservation to conservation actions in aquatic species can be attributed to several factors. In terms of conservationoriented cryopreservation, cultured and "wild" aquatic species share some similarities. Cryopreserved sperm banks are typically created for the conservation of genetic resources of rare breed, threatened or endangered species. In the case of cultured fish, 
these gene banks can be used for the genetic improvement of population diversity. when it faces the problems of low genetic variability. However, in all cases this means further human intervention on fish culture practice.

On the other hand, human intervention is considered more controversial for wild populations which are the primary target of conservation programs. In these programs, captive broodstocks are maintained and spawned in order to supply wild populations by the means of restocking. This activity is considered problematic although the advantages of cryopreservation are acknowledged (Fraser, 2008). For example, sperm cryopreservation can conserve a large portion of the genetic variation of the founder generation of a captive broodstock. It can also minimize the effects of inbreeding and domestication (O'Reilly and Doyle, 2007). Problems associated with cryopreserved gene banks in species conservation include the possibility of outbreeding depression if the founding generation (the sperm donors), the generation providing the eggs are genetically distant and changes in environmental conditions during cryopreservation which reduces the chances of survival of a restored population (Fraser, 2008). The most problematic aspect of applying sperm cryopreservation to species conservation is the lack of specific objectives regarding its use in conservation programs. Development of cryopreserved sperm banks for the "worst-case-scenario" is a typical example of poor planning. It does not define the period of storage time and proposes the use of cryopreserved samples only when the population is in imminent danger of extinction or extirpation. If the conservation program is ultimately successful, these samples might never be used. On the other hand, in a really critical situation, cryopreserved sperm alone will not save the population if females are not available. In addition, indefinite storage of cryopreserved samples increases the associated costs which can be problematic for the sponsors of the program. Thus, careful planning and 
cooperation among various parties involved in a given conservation program is a key factor for the successful use of sperm cryopreservation.

Androgenesis is one of the chromosome set manipulation techniques that can be helped by cryopreservation techniques for the restoration of a given species. It involves inactivation of the oocyte genome through irradiation, fertilization of these eggs with the sperm of the donor species and restoration of the diploid (or rather doubled haploid) state of the embryo using a shock (cold, heat or pressure shock) applied during the first mitotic division (Dunham, 2004; Horváth and Orbán, 1995; Komen and Thorgaard, 2007). In principle, androgenesis allows the restoration of a species from the cryopreserved sperm of a single individual using the eggs of a related species. Cryopreserved sperm has been successfully used in androgenesis on sturgeon species (Grunina et al., 2006), rainbow trout (Babiak et al., 2002; Scheerer et al., 1991) and in interspecific androgenesis between common carp and goldfish (Bercsényi et al., 1998), demonstrating the potentials of this technique. On the other hand, the efficiency of androgenesis is low with yields of androgenetic diploid offspring typically below $20 \%$ (Komen and Thorgaard, 2007). In addition, androgenetic offspring will inherit their mitochondria (and mitochondrial DNA) from the female parent, making them hybrids in spite of the paternal origin of their nuclear DNA. Thus, androgenesis is currently rarely considered as an effective means of application of cryopreservation to conservation programs. A viable alternative to sperm cryopreservation and androgenesis is the cryopreservation and transplantation of primordial germ cells, spermatogonia or somatic cells, which are also mentioned briefly in this review.

Sperm cryopreservation should find niches in conservation programs for successful applications. These can include species where the spawning of females and males is difficult to synchronize such as in the case of the European eel (Asturiano et al., 2007) 
or where the probability of capturing both sexes simultaneously is low, i.e. European sturgeon, Acipenser sturio (Williot et al., 2011). Sperm cryopreservation can be used to facilitate the the time needed for the genetic analysis of a given individual and confirmation of its suitability for use in conservation programs (Horváth et al., 2012). Cryopreservation is applied to the conservation program of the marble trout (Salmo marmoratus) in Slovenia, where populations of this species were endangered by hybridization and introgression with the introduced non-native brown trout. Only a few non-introgressed pure populations of the species remained in isolated streams that represented a special environmental value which had to be preserved. The Angling club of Tolmin has developed an action plan for the preservation of genetic resources of the marble trout that included the creation of "sanctuary" streams by translocating fish from pure populations to isolated fishless watercourses, thus, increasing the chances of their survival (Crivelli et al., 2000). Currently, cryopreservation of sperm is applied to this activity by freezing the sperm of wild males in one of the pure populations one month prior to the spawning season. This cryopreserved sperm is then used for the fertilization of eggs from captive females of the identical population in the spawning season. Eyed eggs of these fish are then stocked into the "sanctuary" stream. The captive broodstock can be limited to a few females and fish are not disturbed in their spawning during the spawning season.

Thus, cryopreservation of sperm continues to be an integral part of fish conservation programs. However, successful application of this technique requires a close cooperation of cryobiologists with other researchers and managers.

\subsection{Cryopreservation of sperm from aquarium model species}


As the largest class of vertebrates, fishes offer unlimited versatility for biomedical research. With extensive studies using aquarium fish models, tens of thousands of specific strains and lines have been created, discovered, and catalogued, and are currently housed worldwide as live animals in resource centres, such as the Zebrafish International Resource Center (University of Oregon, Eugene, OR, USA) which holds around 9,000 inbred, transgenic, knockout and mutant strains. However, with the increasing accumulation of new strains every day, it is becoming more difficult to maintain these valuable genetic resources as live animals. Large-scale sperm cryopreservation is needed to preserve these genetic resources. Sperm banking of these fishes can allow the creation, maintenance, and transport of the associated genetic materials more easily and safely, and can represent a readily transferable form of bankable wealth with the ability to accumulate, archive, and catalogue germplasm. In contrast to the large-sized food fishes and mammals, biomedical research model fishes are characterized by small body sizes $(>5 \mathrm{~cm})$, and thus have limited volumes of sperm available from each fish (1-2 $\mu$ l) (Tiersch, 2001; Yang and Tiersch, 2009). This constrains the use of automated processing equipment, especially for samples from individual males. Successful cryopreservation and repository development requires proper arrangement of a sequence of procedures, and the balancing of inputs and outputs between connected steps. For any sequence developed, the production utility and processing costs can be evaluated. Based on the procedures of sperm cryopreservation for major biomedical model fishes such as zebrafish (Yang et al., 2007a), medaka Oryzias latipes (Yang et al., 2010), and Xiphophorus fishes (Yang et al., 2009, 2007b), four major steps can be identified in a basic sequence: i) sample collection and processing, ii) freezing and sorting, iii) frozen storage, and iv) thawing, utilization, and quality assessment. 


\subsection{1- Sample collection and processing}

Sample processing includes sample collection, suspension of sperm in extender, concentration adjustment, and quality assessment. The first two steps can currently be improved only in terms of technical training and increasing the number of personnel involved. Sperm concentration determination is an important factor to be standardized during cryopreservation and in vitro fertilization. However, small sample sizes from aquarium fishes limit standardization because determination methods such as a hemocytometer require a relatively large amount $(\sim 10 \mu \mathrm{l})$. Micro-spectrophotometric methods to determine sperm concentration have been developed (Tan et al., 2010), which require less time (seconds per sample), and minimal sample volume (1-2 $\mu$ of diluted sperm). Equations relating concentration and absorbance have been established for samples collected by stripping, and by crushing of dissected testis of zebrafish, medaka, and Xiphophorus, and the accuracy of these relationships were verified (Tan et al., 2010).

\subsection{2-Sperm freezing and sorting}

Sample packaging can influence the cooling rate during freezing, storage efficiency after freezing, sample identification, and biosecurity. In zebrafish and medaka, glass capillary tubes or cryovials were first used in sperm cryopreservation (Aoki et al., 1997; Draper and Moens, 2009; Krone and Wittbrodt, 1997). To standardize protocols with potential for high-throughput automation, French straws were chosen for sperm packaging with the smallest commercially available volume $(0.25 \mathrm{ml})$ (Yang et al., 2007a, 2010), and were also used with Xiphophorus fishes (Yang et al., 2007b, 2009). The different materials and shapes of these containers result in different heat transfer 
properties during freezing and thawing. Even for the same style of container, differences can exist with products from different manufacturers, which can result in variability of cooling or thawing rates. Therefore, it is necessary to standardize the packaging method to ensure that protocols will be repeatable especially in different laboratories. Also, the choice of packaging container should consider the potential for high-throughput processing, permanent labelling, reliable sealing, efficient storage, shipping, and inventory. Cryotubes $(0.5 \mathrm{ml}$ and $1 \mathrm{ml})$ have become available for cell banking with compatibility for automated handling in 96-well plates and labelling with twodimensional laser etching. It is possible that systems such as these could be used for sperm cryopreservation for model fishes, although more investigation is needed. There is no established coding system for aquatic germplasm. Unlike the dairy industry, the variety of taxa and protocols encompassed by aquatic species would challenge the format applied by the dairy and beef industries (www.naab-css.org). If a universal code for aquatic germplasm is to be developed, it should provide comprehensive procedure descriptions.

Sample freezing can be accomplished for biomedical fishes by methods including placement on dry ice, suspension in liquid nitrogen vapour, and controlled cooling with a programmable freezer. The first two methods are inexpensive and do not need expensive equipment, and thus can be used in field situations. Programmable freezers are typically used to produce accurate and repeatable cooling rates, especially for sperm that are sensitive to small variations in cooling rate during freezing. For example, for medaka sperm, a change of $5^{\circ} \mathrm{C} / \mathrm{min}$ in cooling rate yielded a significant change in postthaw sperm motility (Yang et al., 2010). Therefore, strict control of cooling rate can assure quality and uniformity of cryopreserved sperm. 


\subsection{3- Samples frozen storage}

Storage of frozen samples in vapour-phase $\left(-120^{\circ} \mathrm{C}\right)$ or liquid-phase nitrogen $\left(-196^{\circ} \mathrm{C}\right)$ in a storage dewar is a standard method. During frozen storage, the important considerations are sample identification, potential contamination, and ease of sample inventory. The use of French straws for packaging offers the advantages of permanent alphanumeric and barcode labelling by printer, and complete sealing which prevents transfer of materials (e.g., sperm cells or bacteria) among samples stored in the same dewar (Morris, 2005). When storage is in the liquid phase of nitrogen, another important consideration is floating of frozen samples, especially when small volumes are packaged in lightweight containers with a large air space. Sample sorting into bulk containers for long-term storage is often needed after freezing. This process should be done under liquid nitrogen, and can be time consuming if the labelling is not easily discernible. If samples can be frozen in storage containers without affecting the cooling process, the sorting step could be skipped or minimized, and the process can be accelerated.

\subsection{4- Thawing and quality assessment.}

Standardization of the use of thawed samples for fertilization can increase offspring production, minimize variability, and minimize waste of cryopreserved samples. Fertilization can be standardized and quantified in terms of the sperm number used for specific numbers of eggs (e.g. sperm-to-egg ratio), the associated water volumes and concentrations, gamete holding times, and protocols used for activation of the gametes. In addition, age, body weight, body length, and culture conditions of fish need to be evaluated with respect to identifying correlations with fertilization success. Optimization of these conditions can greatly improve the efficiency of fertilization and 
offspring production. Due to the small sample volumes available from most model fishes, increases in volume need to come from pooling of samples from different individuals. This would enable processing with a high-throughput approach, minimize male-to-male variation, and provide uniform batches of cryopreserved samples that can receive rigorous quality control and evaluation. More importantly, the pooling of samples can greatly reduce the time needed at certain procedure steps such as motility estimation and sperm concentration determination to achieve the goal of high throughput, and substantially reduce the time and sample volume necessary for quality assessment of fresh and thawed samples.

Quality assessment of gametes is an essential component for successful cryopreservation and repository development. A quality assurance program would include assessment at all relevant steps along the process. For example, sperm motility could be assessed at the time of collection, after suspension in extender, after refrigerated storage or shipping of the diluted samples, after cryoprotectant equilibration, and after thawing. This information can be related to fertilization success. Typical quality assessment methods for biomedical fishes include motility estimations by experienced technicians or by use of computer-assisted sperm analysis (CASA), evaluation of various cellular properties by flow cytometry (Daly and Tiersch, 2011), and estimates of DNA damage has been studied by methods such as comet assay. Aquarium fishes have displayed a wide variety of sperm activation modes that range from hypotonic activation (e.g., freshwater fishes such as zebrafish), isotonic activation (e.g., live-bearers such as Xiphophorus) and hypertonic activation (estuarine and marine fishes). This range of sperm behaviours is one of the factors that make it difficult to generalize quality assessment methods for aquarium fishes. Despite this, standardization 
of methods and reporting are necessary for optimizing protocols and approaches for use with biomedical fishes.

The large number of research strains of small-bodied model fishes held at stock centres or laboratories is continuously growing, and expanded capabilities are needed to preserve these valuable genetic resources. As we move forward, the steps involved in large-scale repository of model species or of any other species are summarized in table 1 (Tiersch et al., 2011).

\subsection{Cryopreservation of sperm from other aquatic species}

There are currently 5,161 threatened aquatic species (IUCN Red List 2015), where cryopreservation could benefit from ex situ programs for restocking or even for conservation of wild populations. Aquatic mammals are good examples where research has been conducted with the aim of increasing population in captivity, especially in sea aquaria, as well as monitoring the effects of anthropogenic contamination of wild populations in order to preserve those species in the future. Killer whales (Orcinus orca) are at risk due to bioaccumulation of environmental contaminants and this risk is already associated with adverse effects in sperm motility, sperm production, sperm chromatin integrity and, consequently fertility. A simple methodology for cryopreservation of killer whale sperm was described by Robeck et al. (2004), and more recently a critical evaluation of extenders and freezing methods was performed by the same group (Robeck et al., 2011). Sperm was cryopreserved by these authors using glycerol and cryoprotectants and directional solidification technology, producing a high recovery rate of motile sperm and motility longevity (Robeck et al., 2011). This technology can be used to develop a gamete resource bank for ex situ population management. For the same purpose a program was developed to store sperm from the 
bottlenose dolphin (Tursiops truncatus). Although management tools to ensure the longterm sustainability of ex situ bottlenose dolphin populations have been under development for the last 30 years (reviewed in O'Brien and Robeck, 2010), only recently several reproductive tools (assisted reproductive technologies-ART, artificial insemination -AI, sperm sorting and sex pre-selection) have been combined with a successful protocol for cryopreservation in this species (O’Brien and Robeck, 2010; Robeck et al., 2013).

\section{Fish oocyte cryopreservation}

Fish embryo cryopreservation is difficult because of their large size, low membrane permeability and chilling sensitivity (Zhang and Rawson, 1995, 1998; Zhang et al., 2003). More recent studies have been focused on cryopreservation of fish oocytes and ovarian follicles as they are better candidates than embryos for cryopreservation, e.g. they are smaller in size, have higher membrane permeability, less chilling sensitive and have a less complex membrane system (Isayeva et al., 2004; Zhang et al., 2005a). Studies carried out so far associated to fish oocyte cryopreservation have been mainly focused on model species such as zebrafish (Danio rerio) (Anil et al., 2011; Godoy et al., 2013; Guan et al., 2010) although other marine and freshwater species has also been studied e.g. gilthead seabream (Sparus aurata) (Zhang et al., 2007) and some South American freshwater species (Streit Jr. et al., 2014).

Earlier studies on late stage oocyte cryopreservation were focused on cryoprotectant toxicity studies (Plachinta et al., 2004), oocyte chilling sensitivity studies (Isayeva et al., 2004), oocyte membrane permeability studies (Zhang et al., 2005a) and cryopreservation studies using zebrafish and gilthead seabream with both controlled slow cooling and vitrification (Guan et al., 2008, 2010; Zhang et al., 2007). More recent 
studies have been carried out on both controlled slow cooling and vitrification of isolated oocytes at early stages (Guan et al., 2010; Tsai et al., 2009a; b), studies of controlled slow cooling and vitrification of ovarian follicles in ovarian tissues (Anil, 2013; Godoy et al., 2013), and development of protocols for in vitro culture and maturation of ovarian follicles at late (Seki et al., 2008) and early stages (Anil, 2013; Tsai et al., 2010). Since a review on cryopreservation of fish oocytes was carried out for the work before 2007 (Zhang et al., 2007), this present review will mainly focus on more recent developments in fish oocyte cryopreservation using controlled cooling and vitrification and especially of early stage ovarian follicles together with developments in in vitro culture and maturation of ovarian follicles.

The studies on cryopreservation of isolated late stage (stage III) zebrafish oocytes using controlled cooling showed that the viability of oocytes frozen in $\mathrm{KCl}$ buffer was significantly higher than oocytes frozen in L-15 medium. The results also showed that fast thawing and stepwise removal of cryoprotectant improved oocyte survival significantly, with highest viability of $88.0 \%$ being obtained immediately after rapid thawing when assessed by trypan blue staining. However, after $2 \mathrm{~h}$ incubation at $22{ }^{\circ} \mathrm{C}$ the viability of freeze-thawed oocytes decreased to $29.5 \%$. Results also showed that the ATP level in oocytes decreased significantly immediately after thawing (Guan et al., 2008). Studies on cryopreservation of stage III zebrafish oocytes by vitrification produced similar results to those obtained from controlled slow cooling in relation to oocyte viability (Guan et al., 2010). Vitrification of stage III zebrafish ovarian follicles in ovarian fragments was also studied by Godoy et al. (2013). The results showed that although membrane integrity of stage III ovarian follicles in ovarian fragments was slightly lower than in those obtained from isolated stage III ovarian follicles after vitrification, the follicles remained opaque and morphologically intact when compared 
with isolated follicles described by Guan et al. (2010) as became swollen and translucent after vitrification.

Studies on early stage zebrafish oocytes indicated that early stage ovarian follicles (stage I and II) are less sensitive to chilling injury than late stage ovarian follicles (Tsai et al., 2009a). The results from cryopreservation of isolated follicles using controlled slow cooling showed that ovarian follicle viability for early stages was higher $(41.7 \%$ and $65.8 \%$ for stage I and II respectively) than stage III (29.5\%) after cryopreservation and 2 hour culturing but ADT:ATP ratios were significantly increased (Tsai et al., 2009b). Cryopreservation of zebrafish ovarian tissue fragments containing ovarian follicles at different stages has also been studied (Anil, 2013). The optimal cryopreservation protocol for the ovarian tissue fragments was found to be $2 \mathrm{M}$ methanol $+20 \%$ FBS in $90 \% \mathrm{~L}-15$ medium with the cooling rate of $4{ }^{\circ} \mathrm{C} / \mathrm{min}$. The highest survival rate obtained for stage II follicles within the fragments was $68 \%$ and stage I follicles within the fragments was 55\% using trypan blue staining. These studies, performed by Anil (2013), provided an improved cryopreservation protocol since it enhanced the viability of stage I and II follicles with the use of $2 \mathrm{M}$ methanol $+20 \%$ FBS in $90 \%$ L-15 medium when compared to the previous protocols developed by Guan et al. (2008) and Tsai et al. (2009b). However, the results obtained from ATP assay also showed compromised survival of the ovarian follicles after cryopreservation (Anil, 2013).

Another challenge associated with developing cryopreservation protocols for fish oocytes is the development of successful protocol for in vitro maturation of oocytes after cryopreservation. Although a successful protocol has been developed for in vitro maturation of late stage III zebrafish oocytes which supported their ability to be fertilized and to develop until hatching (Seki et al., 2008, 2011), in vitro maturation of 
earlier stages of ovarian follicles has not been studied until more recently. Studies on in vitro culture of stage I and stage II ovarian follicles demonstrated that early stage zebrafish ovarian follicles can be cultured in vitro for $24 \mathrm{~h}$, stage I and II ovarian follicles can grow to the sizes of early stage II and early stage III ovarian follicles after hCG treatment (Tsai et al., 2010). More recent studies have been focusing on the development of in vitro culture methods for ovarian tissue fragments containing stage I and stage II follicles. The results showed that stage I and II follicles can be cultured invitro for $24 \mathrm{~h}$, treated in 90\% L-15 medium (pH 9) containing $100 \mathrm{mIU} / \mathrm{ml} \mathrm{FSH}$ with $20 \%$ FBS. It showed ovarian follicle growth competence from stage I to stage II and from stage II to stage III respectively. The growth assessment was also confirmed by determining the expression of P450arom $\mathrm{A}$ and $\mathrm{Vtg} 1$ gene which were used as biomarkers for stage II and stage III ovarian follicle development (Anil, 2013). Some recent studies have also been carried out on other species such as South American fish species Colossoma macropomum. Digmayer (2013) assessed the viability of Colossoma macropomum oocytes in $1.6 \mathrm{M}$ methanol and glucose, sucrose, trehalose or fructose $(0.25$ and $0.50 \mathrm{M})$ using controlled slow cooling. The SEM analyses following cryopreservation showed that oocytes maintained some intact morphological structures, such as the micropyle when $1.6 \mathrm{M}$ methanol and $0.25 \mathrm{M}$ sucrose was used. In summary, studies carried out so far on cryopreservation of fish oocytes indicated that better results were obtained with early stage ovarian follicles such as stage I and stage II with stage II ovarian follicles being the most promising candidates. Vitrification of these ovarian follicles also produced some initial promising results. More work needs to be carried out in optimising the protocols for both cryopreservation and in vitro maturation of fish ovarian follicles. 


\section{Fish embryo cryopreservation}

Fish embryo cryopreservation has been a challenging objective for decades and is yet to be achieved. Persistence of scientists in developing protocols for fish embryo cryopreservation after a number of unsuccessful trials can be explained by the advantages associated with successful fish embryo cryopreservation. From a conservation point of view, successful cryopreservation of fish embryos would ensure the preservation of both paternal and maternal genome; from an aquaculture point of view, successful fish embryo cryopreservation would significantly simplify the establishment and management of genetic selection programs in fish farms. Challenges hindering fish embryo cryopreservation are well known and could be summarized in four areas: fish embryos have low surface-to-volume ratio, large size of yolk, low membrane permeability and high chilling sensitivity (Hagedorn et al., 1997a,b; Zhang and Rawson, 1998; Zhang et al., 2003). In this section, different approaches used during the last decades for fish embryo cryopreservation will be reported including limited success reported together with future perspectives. Embryo sensitivity to chilling and cryopreservation has been studied in over 20 teleost species (Table 2). However, only embryo chilled storage has resulted in successful embryo development in different species (Fornari et al., 2014; Liu et al., 2001b; Pessoa et al., 2014; Robles et al., 2007). Reports on embryo survival after cryopreservation (controlled slow freezing or vitrification) has been very limited (Chen and Tian, 2005; Robles et al., 2005) although Chen and Tian's results have been disputed (Edashige et al., 2006). Fish embryo cryopreservation studies can be grouped into four main categories: i) studies involving cryopreservation protocol development such as toxicity of different cryoprotectants, freezing/thawing rates, optimium species or embryo developmental stage for cryopreservation, ii) studies on membrane permeability and 
cryoprotectant penetration, iii) studies that aim to provide new methods or tools for evaluating embryo viability/survival after freezing/thawing, and iv) studies that aim to provide new technologies or procedures that improve fish embryos' ability to be cryopreserved. A recent systematic review on fish embryo vitrification protocols established that, in most of the studies, the major aspects to be considered for the development of new vitrification protocols are cryoprotectant toxicity, embryo developmental stage, conditions under which embryos were exposed to cryoprotectants and vitrification devices (de Carvalho et al., 2014). Most of the studies on fish embryo vitrification fall within the area of toxicity of vitrification solutions. Considering that fish embryos at different stages possess different barriers to cryoprotectant penetration, some studies have also been carried out using different methods to evaluate cryoprotectant flux or concentration within the embryos at diferent stages. Impedance spectroscopy (Zhang et al., 2006), magnetic resonance microscopy (Hagedorn et al., 1996), HPLC (Cabrita et al., 2003) and scanning calorimetry studies (Liu et al., 2001a) have all been used for this purpose. The scarce report of embryo survival after freezing/thawing has pushed some researchers to explore different methods for evaluating cryopreservation protocols. These studies intend to combine observational methods (morphological studies) with molecular biological methods in order to provide more information on embryo metabolism at enzymatic level (Robles et al., 2004) or molecular level (Desai et al., 2011). Finally, studies have also been carried out with the aim of modifying the embryos in order to overcome some of the problems associated with their cryopreservation. These studies explored the use of microinjection in delivering cryoprotectants into the embryos (Janik et al., 2000), incorporation of antifreeze proteins (AFP I, AFP III) within the embryos (Martínez-Páramo et al., 2008, 2009a; Robles et al., 2007), partial yolk removal to reduce chilling sensitivity (Liu et al., 
2001b), the use of ultrasounds to increase cryoprotectant penetration (Wang et al., 2008) or even altering fish embryo membranes with aquaporin 3 to increase permeability (Hagedorn et al., 2002).

Despite all these efforts, successful fish embryo cryopreservation remains elusive. However recent studies on cryopreservation of primordial germ cells have provided a promising alternative for the cryopreservation of both paternal and maternal genomes. By recovering the primoridal germ cells from vitrified embryos, and transplanting them into sterile recipient larvae, Higaki and collaborators $(2009,2010,2013)$ achieved the production of fertile zebrafish. This is undoubtedly a promising area of study, which must be explored until fish embryo cryopreservation can be achieved.

\section{Spermatogonia and primordial germ cell cryopreservation}

From the successful cryopreservation of sperm from numerous fish species, allowing the preservation of the paternal genome to the several studies on fish oocytes and embryo cryopreservation, still representing a bottleneck in the preservation of the maternal genome, several attempts have been made to search and preserve other type of cells that could guarantee all individual genome cryobanking. Primordial germ cells, spermatogonia and oogonia have been explored as an alternative reproductive material to answer this problem and have been cryopreserved successfully in several fish species (Robles et al., in press; Yoshizaki et al., 2011). These cells can represent a good opportunity to store individual genome, being possible, with the application of reproductive biotechnological tools, such as transplantation, to restore and individual or a species. There are several applications of cryopreservation of stem germ cells that have been reviewed elsewhere (Robles et al., in press; Yoshizaki et al., 2011). 


\section{Somatic cells: strength and pitfalls of preservation and regeneration}

The use of differentiated somatic cells for genome preservation, including the cryopreservation, the culture, and fish regeneration by nuclear transfer were reviewed previously (Chenais et al., 2014), and the reader is referred to this review for comprehensive description and discussion of the different steps at stake. The present subsection will emphasize the main bottlenecks and the research efforts still necessary to make the involved technologies more reliable.

In the context of genome preservation, somatic cells can be limited to differentiated cells which are collected on adult fish or on developing embryos after epiboly. This excludes the embryonic fish cells collected before the embryonic genome activation. The main outcome in using those early embryonic cells is to recover primordial germ cells either directly within the blastula or after culture (Riesco et al., 2014). Some reviewed information on embryonic stem cells which have been studied for more than 20 years (Ma et al., 2001; Sun et al., 1995; Wakamatsu et al., 1994) can be found in Barnes et al., (2008), Hong et al., (2011), Labbé et al., (2013), and Robles et al., (2011). Somatic cells are diploid, so their advantage in genome preservation is that they transmit both maternal and paternal genome. Besides, somatic cells can be collected independently of the sex or age of the fish and still bear the same interest for genome preservation. Skin and fin in fish are good candidates for tissue collection because of their regenerative capacity (Akimenko et al., 2003; McDonald et al., 2013; Poss et al., 2003). This is especially important in the case of endangered fish or unique specimen, where no drastic injury should impair the precious individual. Besides, fin cells are among the best donor cells for fish regeneration by nuclear transfer (Siripattarapravat et al., 2011). Collection of somatic cells from developing embryos can be trickier as it will require chorion removal (by enzymatic digestion or mechanical shearing) and that after 
collection of few cells, the embryo is incubated into media with specific ion composition before reaching the hatching stage, in order to cope with the loss of the chorion barrier.

\subsection{Tissue collection and cryopreservation}

Once the tissue is collected, it must be maintained in culture in order to increase the cell number before cryopreservation, or frozen to store the tissue piece until the regeneration of the fish is necessary. When many fish are collected at the same time, it can become costly and practically impossible to set cell culture for all samples. One alternative is to cryopreserve tissue pieces just after collection, as successfully explored in Moritz and Labbe (2008). In all cases, although it is common to freeze cultured cells or tissue pieces in cryovials, we advice to set up procedures where the samples can be cryopreserved in straws. Indeed, almost every fish sperm cryobank is equipped for straws (cryopreservation, straw printing, storage tanks), and it should be foreseen that the somatic samples will incorporate the same banks. Apart from this requirement, cryopreservation of fin pieces or of cultured cells does not raise specific difficulties (Chenais et al., 2014).

In the context of fish regeneration, enough cells can be recovered from a few milligrams of tissue. However, in some cases optimization of the culture conditions should be planned, and this can be made separately from the sampling and cryopreservation process. Methods to obtain cultured cells from fish tissues have been developed for many species (Lakra et al., 2011), but the culture quality and the growth capacity of the cells can be variable (Chenais et al., 2014). This may require some culture conditions adjustments which are not always handy. For example, the yield of cell production may be better with thin pieces than with thicker ones, likely because of a more 
heterogeneous cell population in the later (Labbe et al., 2011). Also, although most species can be cultured with quite standard culture conditions, some are more demanding and specific growth factors may be needed (Collodi et al., 1992).

\subsection{Fish regeneration by nuclear transfer}

The main method to regenerate a fish from somatic cells is nuclear transfer (Chenais et al., 2014), also called cloning. In the most efficient conditions (Bail et al., 2010; Hattori et al., 2011; Siripattarapravat et al., 2009), nuclear transfer in fish consist in injecting the whole cell, or only the nucleus, into an oocyte previously enucleated, or not, and previously activated, or not. The whole purpose of the procedure is that the recipient oocyte will reprogram the injected chromatin so that a proper embryonic development will take place. Nuclear transfer allows that the offspring bear the nuclear DNA from the donor animal. It is important to understand that the embryo is developing thanks to the oocyte material (proteins, mRNA, mitochondria), and that in most cases, mitochondrial DNA from the donor animal is lost in the offspring (reviewed in Chenais et al., 2014). The extent and consequences of this mitochondria loss have not been explored yet in fish. A better understanding of the consequences, or of the lack of, may help to identify to which extent the produced clones are truly nucleo-cytoplasmic hybrids.

The strength of regeneration by nuclear transfer is that the recipient can belong to a species which is different from that of the donor one (Sun et al., 2005; Yan et al., 1985). This ability raises the major question of the best recipient species for an array of donor, in a situation where few species easily obtained in aquaculture could provide good quality oocytes for a high number of donor. Some research is still needed to understand the requirement for embryo development in such nucleo-cytoplasmic hybrids (Chenais 
et al., 2014). For example, the number of mitochondria and the yolk composition and quantity in the oocyte should meet the energy requirement of the developing embryo. We also know too little about the epigenetic influence of the oocyte cytoplasm on gene regulation of the foreign donor chromatin.

\subsection{The challenge of somatic cell reprogramming}

As previously reviewed (Chenais et al., 2014), many embryos showing a normal early development after nuclear transfer are dying at the onset of embryonic genome activation, or show some malformations once the organs are developing. Because most abnormal clones show aberrant gene expression (Biddle et al., 2009), including in fish (Luo et al., 2009; Pei et al., 2007), it was hypothesized that the epigenetic control of silencing the right set of genes or of allowing expression of another set of genes is flawed. Indeed, during early development, the parental chromatin undergoes extensive epigenetic reprogramming driven by the oocyte factors in order to allow the proper establishment of the gene expression pattern in the embryo (Robles et al., in press). Failure in clones means that the gene expression pattern of the differentiated cell is not faithfully reset towards an embryonic pattern.

This reasoning led to investigate the benefit of treating the donor cells and the clones with epigenetic drugs which were initially developed to understand cancer mechanism and stem cell pluripotency. Some drugs are targeting inhibition of DNA methylation (Eilertsen et al., 2007), with the 5-aza-2' deoxycytidine (aza-dC) among the most used. Aza-dC acts as an analogue of the cytosine base with the loss of methylation ability. However, the most efficient drugs for reprogramming donor cells for nuclear transfer are targeting histone acetylation, by way of HDAC (histone deacetylase) inhibitors (Biran and Meshorer, 2012; Gaspar-Maia et al., 2011) with trichostatin A (TSA) as the 
most widely tested molecule (Enright et al., 2003; Luo et al., 2013). Another reprogramming strategy in mammal is to use oocyte extracts, mainly from Xenopus (Liu et al., 2014). These reprogramming treatments are to be tested on fish cells, either before or after cryobanking. The fact that the embryonic genome activation takes place after up to 10 mitoses in fish (Kane and Kimmel, 1993) (when it takes 1 to 3 mitoses only in mammals) should favour the positive action of the reprogramming treatment in those species.

One last reprogramming strategy for somatic cells lies in their trans-differentiation into germ cells, so that they can be used to produce gametes after transplantation (see Robles et al., in press). This strategy finds its roots in the work of Takahashi and Yamanaka (2006), where adult mouse fibroblasts in culture could be reprogrammed into pluripotent cells (iPSC for induced pluripotent stem cells), the later being able to develop into the three embryonic germ layers. From then on, many groups tried to reprogram differentiated cells into other types of differentiated cells via iPSCs, including germ cells (Ishii, 2014). The most advanced works are found in mouse (Cai et al., 2013; Imamura et al., 2010) and human (Ishii, 2014). Although fully functional gametes could not be obtained yet, this strategy should not be forgotten among the panel of biotechnologies for fish regeneration from somatic cells.

\section{Germplasm cryobanking of invertebrates}

As in other species, germplasm cryobanking of invertebrates has a twofold benefit: it is the perfect tool to preserve genetic diversity and it has evident benefits for aquaculture industry. Coral reefs are a clear example of the need of cryopreservation for conservation purposes. Human activities have a deep impact in coral reefs degradation, and successful cryopreservation protocols could guarantee genotypes preservation until 
habitats could be rehabilitated (Hagedorn et al., 2012). Regarding aquaculture industry, cryopreservation would contribute to reduce broodstock cost and to have a fine control of several reproductive aspects (Adams et al., 2004). As in fish, there are several biological materials that can be preserved including germ cells (spermatogonia and sperm), and contrarily to fish there are successful attempts to cryopreserve other materials such as spermatophore (capsule containing sperm cells), oocytes, embryos and larvae.

\subsection{Sperm and spermatophores of invertebrates}

Sperm cryopreservation has been studied in several species of invertebrates. Several species of oysters have been the main focus of such studies: pearl oyster (Pinctada margaritifera) (Acosta-Salmón et al., 2007); Japanese pearl oyster (Pinctada fucata martensii) (Kawamoto et al., 2007); Pacific oyster (Crassostrea gigas) (Dong et al., 2005; Dong et al., 2006); Eastern oyster (Crassotrea virginica) (Paniagua-Chavez and Tiersch, 2001); Ostrea edulis (Vitiello et al., 2011) and Portuguese oyster (Crassostrea angulata) (Riesco et al., in press). Different studies on cryopreservation and cold storage of spermatozoa from Echinoderms have also been performed during more than three decades (Adams et al., 2004; Dunn and McLachlan, 1973; Spiegler and Oppenheimer, 1995). Mussels (Mytilus galloprovincialis) (Di Matteo et al., 2009); abalones (Haliotis laevigata) (Liu et al., 2014); tunicates (Ciona intestinalis) (Sorrenti et al., 2014); and shrimps (Sicyonia ingentis) (Anchordoguy et al., 1988) and (Litopenaeus vannamei) (Lezcano et al., 2004) have also been considered important targets for sperm cryopreservation. All these studies are mainly focused in designing a cryopreservation protocol successful in terms of sperm viability and motility, and are basically centred in studying different cryoprotectants and freezing rates (Acosta- 
Salmón et al., 2007; Ieropoli et al., 2004), different equilibration times in cryoprotectants or different types and sizes of straws (Dong et al., 2005, 2006). Fluorescent dyes have been used in some of these studies to evaluate sperm cell membrane integrity and mitochondrial function (Lezcano et al., 2004; Paniagua-Chávez et al., 2006). Comet assay (Single cell gel electrophoresis assay) has been successfully used in oyster to detect DNA damage after cryopreservation (Gwo et al., 2003). Spermatophore cryopreservation has been tried in some invertebrate species, from shrimps (Penaeus monodon) to cephalopods (Illex coindetii). The first case reported viable spermatozoa for up to 210 days (Vuthiphandchai et al., 2007). However, cephalopod spermatophore cryopreservation is challenging. The study performed in the squid, Illex coindetii determined by flow cytometry sperm post-thaw viability and mitochondrial activity using Mitotracker deep red, YOPRO1 and Hoechst 33342 after testing different cryoprotectants, concentrations and freezing/thawing rates. This study pointed to DMSO as an appropriate cryoprotectant for this species, and represented the first approach on spermatophore cryopreservation in this group of molluscs (Robles et al., 2013). DMSO has also been suggested as a good cryoprotectant for gorgonian coral sperm sacs by testing mitochondrial activity by an ATP luminescence assay (Tsai et al., 2014).

Despite the remarkable effort in developing successful sperm cryopreservation protocols for all these species, much work has still to be done, particularly in standardization (Dong et al., 2005), before most of these protocols could be used on a commercial scale. From a conservation point of view, efforts towards coral biodiversity preservation yield promising results, and the first frozen repository of coral has been created (Hagedorn et al., 2012). The establishment of genetic banks will undoubtedly 
help in the conservation of valuable areas such as the Great Barrier Reef (Hagedorn and Spindler, 2014).

\subsection{Embryos and larvae of invertebrates}

Contrary fish species, the success of the cryopreservation of invertebrate embryos or larvae is favoured by some biological characteristics such as a limited embryo size improving water and cryoprotectant exchange, a low yolk content in the oocyte and a holoblastic cleavage improving cryoprotectant penetration (Robles et al., 2008). Since the pioneering work published by Renard (1991), 40 studies have been published in few invertebrate species (Figure 4).

The increasing interest in embryo cryopreservation in invertebrate species may be explained by the recent improvement of farming techniques, including breeder selection and creation of special lines such as tetraploids: the genome of these embryos must be preserved. Embryo or larva cryopreservation studies have mainly focused on Pacific oyster because of its high commercial value. Whatever the species, the survival remains limited $(<1 \%)$ but promising because of the high quality of surviving thawed larvae observed in a few long-term studies.

Most published studies aim at defining a cryopreservation protocol, including the main points classically investigated: cryoprotectant nature and concentration, freezing rate, embryo concentration in straws and thawing conditions. Preliminary studies investigate the cryoprotectant toxicity tolerance of embryos at room temperature: compared to ethylene glycol (EG), DMSO appeared to be less toxic for Pacific oyster embryos (Chao et al., 1994). On the contrary, EG gave a better survival than DMSO after freezing and thawing (Choi and Chang, 2014). Furthermore, EG was less toxic to sea urchin (Evechinus chloroticus) larvae than DMSO, while no larvae survived after freezing and thawing using EG (Adams et al., 2006). These contradictory results suggest that toxicity 
studies do not take into account the possible interactions of the cryoprotectant with the following steps of the cryopreservation process. Adding sugars (glucose or sucrose) improved the post-thaw survival of Pacific oyster (Renard, 1991) and of pearl oyster (Choi and Chang, 2003) by reducing the toxicity of cryoprotectants and decreasing injuries of thawed embryos. However, adding trehalose did not improve the post-thaw survival of blue mussel embryos (Wang et al., 2011). Regarding embryo development stage, the consensus view is that the trochophore stage is best adapted to cryopreservation in Pacific oyster (Gwo, 1995; Usuki et al., 2002), but not in pearl oyster, the best survival being observed at the D-larval stage (Choi and Chang, 2003). However, from thawing up to the adult stage, the survival of Pacific oysters cryopreserved at the trochophore stage was lower than the results observed after cryopreservation at the D-larval stage: 0.05 and $0.15 \%$, respectively (Suquet et al., 2014).

Particular attention must be paid to three questions which are not strictly related to the basic cryopreservation technique: i) the problem of the assessment of embryonic or larval survival, ii) the inter-female variations of embryo survival after thawing and iii) the long-term rearing performances of thawed larvae. The survival of thawed mollusc embryos was generally estimated by assessing the percentage of motile larvae: just after thawing, 20 to $40 \%$ Pacific oyster larvae are motile, while only one larva succeed to settle after 29 days rearing (Usuki et al., 2002). The decrease of larval movement velocity observed using a CASA system, is suggested to be a more reliable estimation of the quality of thawed Pacific oyster larvae (Suquet et al., 2012).

Inter-female variations of embryo survival after thawing were first suggested by Renard (1991), showing the higher the development rate of the control (non cryopreserved embryos), the better the survival of thawed Pacific oyster embryos. More precisely, 
Paniagua-Chavez and Tiersch (2001) observed that control Eastern oyster larvae having a low survival rate $(<40 \%)$, also have a low cryopreservation ability. The survival after thawing can be improved by broodstock conditioning regime (Adams et al., 2013). However, the effect of several factors (genetic, physiological, environmental) which can be responsible for such individual variations must be investigated.

Studying the long-term rearing performances of thawed embryos is a prerequisite to the development of embryo cryobanking. Four month after thawing, the survival of oysters was not different from the control (Paniagua-Chavez et al., 2000). Close to three years after embryo thawing, the growing-out and reproductive capacities of Pacific oysters were similar to those observed for unfrozen ones (Suquet et al., 2014). Both examples suggest an absence of genome alterations of thawed embryos, allowing subsequent development of these oysters and their use in cryobanks.

In conclusion, although the survival of thawed mollusc embryos remains low, this technique looks promising because this result may be largely increased by further technical improvements, sustained by a better knowledge of biological characteristics of mollusc larvae. Then, this technique can be applicable for the establishment of mollusc embryo cryobanks in species for which high long-term rearing performances have been confirmed.

\section{The need for standardization}

Cryopreservation methods are developed by scientists for various purposes; however, the main objective of the development of this methodology is application to practice. Cryopreservation is essentially an applied area of science, cells are rarely cryopreserved only for the sake of novel biological information on their behaviour at ultra-low temperatures. The purpose of methodical development in fish sperm cryopreservation 
can be - among others - to assist reproduction in aquaculture (Bokor et al., 2010;

Linhart et al., 2005), to apply in selective breeding programs (Adams et al., 2008) or to apply in species conservation actions (Viveiros and Godinho, 2009).

Nevertheless, the use of cryopreservation methods in aquaculture is very limited or is applied on individual basis, not systematically as part of a greater industry. The reasons for this rejection can be various: sperm is seldom a limiting factor in induced fish spawning, selective breeding is applied only to a handful of aquaculture species and finally, sperm cryopreservation methods are not standardized or universally accepted as they are in the cryopreservation industry serving domestic livestock farming. Adoption of cryopreservation into aquaculture practice is further hindered by the lack of consensus among scientists on standard protocols in a given species. For instance, cryopreservation of eel sperm has been reported for the first time in the Japanese eel Anguilla japonica (Tanaka et al., 2002). In the European eel (A. anguilla), two teams started to work on the species independently of each other, a Spanish team building on the experiences of the previously mentioned experiments on the Japanese eel and developing their own media for cryopreservation (Peñaranda et al., 2009) and a Hungarian team building on their previous experience in common carp (Magyary et al., 1996) and later developing their methods based on those of Tanaka et al. (2002) (Müller et al., 2012). This demonstrates the abundance of cryopreservation methods developed by several teams independently for a single species without intercalibration or standardization of their protocols.

Standardization of existing methodologies can be achieved by systematic optimization of factors affecting the quality of the product, intercalibration of methods by a reference laboratory or by the simple adoption of one of the methods by the industry. Systematic optimization of methodologies has been carried out in a number of species including the 
Pacific oyster, Crassostrea gigas (Dong et al., 2005, 2006) or the zebrafish (Yang et al., 2007a) and includes careful analysis of factors such as cooling rates, cryoprotectants and their concentrations as well as sperm concentration. Intercalibration of existing methods can be a complicated process that may take several decades to complete (Poikane et al., 2014), and to the best of our knowledge this has not been carried out in cryopreservation science. This type of standardization is typically monitored by international organizations such as FAO (EIFAC, 1986) or WHO (WHO, 2010) and can later serve as a gold standard for scientists and professionals of the given area. Adoption of a given protocol by the industry is simpler procedure. The adoption of the Tris-egg yolk-glycerol method to bull sperm freezing has resulted in its acceptance as a standard industry protocol (Walters et al., 2009). Adoption by the industry also involves quality control to reduce variability in the use of standardized protocols and branding of the protocol or its components as a product. Quality control of high-throughput cryopreservation of sperm has been described in detail for the blue catfish Ictalurus furcatus (Hu et al., 2013).

Standardization in reporting the results of cryopreservation studies is also an important factor that can affect the reproducibility of the given protocol. There is a significant variation in the use of terminology in cryopreservation science. A typical example is the interchangeable use of the terms "extender" and "diluent" which may (Cabrita et al., 2001; Ciereszko et al., 2014; Lahnsteiner et al., 1996) or may not (Kurokura and Hirano, 1980; Kusuda et al., 2005) contain cryoprotectants. There is also a lack of consensus whether cryoprotectant concentrations should be given relative to the extender (Lahnsteiner et al., 1996; Robles et al., 2003a; Rurangwa et al., 2001) or to the final dilution with sperm (Linhart et al., 2000; Rodina et al., 2007). A significant effort 
has been made to reduce these ambiguities in reporting cryopreservation results (Benson et al., 2013), however, more specific guidelines might be necessary for aquatic species.

\section{The cryopreservation industry}

In mammals, the cryopreservation of gametes and embryos has been developed as a very profitable business; however, in aquatic species this technique is far to reach this level. In the last years, the increasing need of reproductive assisted treatments in humans have promoted the use of cryopreserved oocytes and sperm (RodriguezWallberg, 2015). Recent findings have demonstrated the multiple applications of stem cells, leading to the apearance of cryobanks for cord blood stem cells used for medical purposes (Pineault and Abu-Khader, 2015). In other non-human mammals, similar companies have been developed with the aim of using cryopreservation as a tool in selective breeding programs. For instance, in cattle, the use of cryopreserved sperm from selected breeders is extensively used to maintain the genetic traits in a selected population (Thurston and Watson, 2002). In fish, the idea to develop selective breeding programs to improve productivity in aquaculture has been taking special attention during the last years (Lind et al., 2012). Thus, biotechnological companies have realized the profitable point of view of this field, and their growing offer in cryobanking services for fish sperm is increasing. Problems associated with disease-free control of horizontal pathogens transmission help to understand that cryopreservation of sperm could be one of the solutions to guarantee safety use of biological material for the production of new generations. Another target market is in the recovery of endangered species by cryopreserving sperm from individuals with low effectives or in fish model organisms, such as zebrafish, to preserve genetic material of selected strains with biotechnological interest. All procedures are standardized for an effective fish reproduction, including development of media to increase sperm and egg quality, to ensure optimal activation of 
the sperm cells, or for short-term storage of milt when cryopreservation is not needed. Presently, cryopreservation services are available for several fish species (http://www.cryogenetics.com/), specially salmonids like Atlantic salmon (Salmo salar), rainbow trout (O. mykiss), coho salmon (O. kisutch), chinook salmon (O. tshawytscha), Arctic char (Salvelinus alpinus), sockeye salmon (O. nerka), brown trout (Salmo trutta), brook trout (Salvelinus fontinalis), and other species like sablefish (Anoplopoma fimbria), zebrafish (D. rerio), and lumpsucker (Cyclopterus lumpus). Tailoring your needs could be also done by developing specific protocols based on customer demands. Specific media have also been commercialized for gamete preparation (http://www.imv-technologies.com/). Thus, there are companies providing different media to dilute sperm for short-storage or cryopreservation, or to optimize motility activation. According to manufacturers, these media can be used for a wide range of species like salmonids, turbot, gilthead seabream or tilapia.

Despite that cryopreservation industry in aquatic species is scarce compared with the one in mammals, a significant increase is expected in the next decade, since research in aquatic species and aquaculture industry are probably two areas that have been suffering technological advancements in recent years. Thus, considering the usefulness of cryopreservation as a tool for selective breeding programs, more market and business opportunities can appear in the near future.

\section{Cryobanking worldwide}

\subsection{European cryobanks}

Several cryobanks were developed in Europe over the last 30 years, with a common purpose of conservation of the genetic diversity from wildlife and from farmed resources (Table 3). Because no shared European repertoire is available, an exhaustive 
list of those banks is difficult to establish. Additionally, because each bank was established independently in every country, the way they are run is very heterogeneous, and the quality of the collections is impossible to state on a general scale. In the COST Action AQUAGAMETE (FA 1205; http://aquagamete.webs.upv.es/), some common and standardized cryopreservation procedures should be proposed to these cryobanks, but a lot is to be done before the different collections can be displayed and proposed to the European community of researchers, breeders, or conservation biologists. So far, we have only few examples where these collections are used, either because the bank is not organized for collection providing, or because the information on the genetic resource is difficult to find for the putative user.

\subsubsection{European cryobanks for wildlife conservation}

To our knowledge, one of the oldest fish cryobank in Europe was established in the former USSR, under the supervision of Dr E. Kopeika (Head of the Department of Reproductive System Cryobiology Institute for Problems of Cryobiology and Cryomedicine of National Academy of Science of Ukraine). Back in 1981, the head of the department of animal breeding and genetics VNIIPRKh (All-Union Scientific Research Institute of Pond Fisheries, Moscow district), Dr Katasonov signed with the Ukrainian Institute an economic agreement (1981-1985) to create the Cryobank of Carp sperm. The VNIIPRKh was developing different new breeds of carp and asked the Ukrainian Institute to cryopreserve sperm of all these lines. Besides breeds from that institute, they also cryopreserved sperm of carps from different regions of the former USSR (Krasnodarsky region, Tula region, Habarovsky region, and other areas). They also had sperm from German, Romanian, Hungarian, Zagorski, Parsky and Cherepetsky carp breeds. Very importantly, all collected samples at the time were brought into two 
locations. One location was in the Cryobank at VNIIPRKh (Moscow suburban) and the second was in the Ukrainian Institute in Kharkov. By 1985, the bank was officially established, and more samples were added to both banks until 1990. However, starting from 1990, any newly collected samples were taken only to the Ukrainian Institute. Today, the Ukrainian Cryobank is still there with 500 litre storage space filled completely with cryopreserved sperm from different fish species, although the latest samples were cryopreserved in 2010. Liquid nitrogen is supplied by a weak budget of the Institute. The stored resources are utterly valuable, with some of the samples more than 30 years old. The bank contains frozen sperm of species that are close to extinction such as aral thorn or ship Acipenser nudiventris Lovetzky, 1828, Huso huso Linne, 1758, from Azov Sea, green sturgeon (A. medirostris Ayres, 1854) from the Far East, stellate sturgeon (Acipenser stellatus Pallas, 1771), sterlet (Acipenser ruthenus Linne 1758) from the Caspian Sea, Russian sturgeon (Acipenser guldenstadti colchicus Brandt., 1833) sperm from Berdyansk, troepera (Tripterygion tripteronotus Russo, 1810), species from the Black Sea. Other species include trout from the river Rioni, pink salmon (Oncorhynchus gorbuscha Walbaum, 1792) caught in Kamchatka, different carps from the Khabarovsk territory (wild form Cyprinus carpio haematopterus temminck Schlegel, 1842), and mullet (Mugil cephalus Linnaeus, 1758) from Azov Sea. This bank is a unique resource for either agricultural breeding program, when some crossing of species is required, or restoration programs for endangered species.

More recently, the Frozen Ark project (http://www.frozenark.org/) was launched in the 2000 in the UK, with the establishment of a major new cryofacility at the Natural History Museum in London. Although not dedicated to reproductive tissues and cells, the project aims to conserve the genetic resources of the world's endangered species 
with an international consortium of centres that hold frozen tissues, cells and DNA samples of many animal species. As part of the frozen Ark project, University of Bedfordshire (UK) has established a cryobank for critically endangered fish species as well as a specimen cryobank for UK fish species. The specimen collection of the cryobank began in June 2008 and the collection of the specimens of freshwater species was made in collaboration with the Environment Agency in England, the collection of specimens of marine species was in collaboration with the Centre for Environment, Fisheries \& Aquaculture Science (Cefas) and the collection of non-UK species was in collaboration with Zoos and Aquariums in the UK. The cryobank currently holds 112 species of fish - 94 marine and 8 freshwater from UK waters, and 10 tropical species. None of the samples are related to farmed fish lines. In total 624 vials of tissues and cells have been banked and in all cases fin clips have been banked to preserve cell viability and cell lines have been established from 24 of the 112 species. Muscle tissue has also been cryopreserved to ensure long-chain DNA integrity, and in the case of marine species, blood samples are held on Whatman FTA cards.

The Cryo-Brehm project in Germany is a member of the Frozen Ark consortium. The common aim is to secure a variety of scientific samples of wild animals before they become extinct. Cryo-Brehm was initiated in 2007 by the Fraunhofer-Gesellschaft zur Förderung der angewandten Forschung e.V. with its Research Institution for Marine Biotechnology (EMB), the Fraunhofer Institute for Biomedical Engineering (IBMT), the Zoo Rostock and the "Tierpark Hagenbeck" zoo of the city of Hamburg. Recently, the Sea-Life Centre Timmendorfer Strand joined the consortium. Cryo-Brehm has conservation purposes, but with the additional aim to establish cell lines from the collected samples, for research or veterinary purposes. More than 80 cell cultures were collected from 20 fish species, 8 freshwater and 12 marine species. Vials of untreated 
tissues from even more fish species are banked at Cryo-Brehm. The collected cell cultures derive from organs like heart, skin, spleen, head-kidney, liver, brain, testis, pancreas, pylorus or pituitary gland. More recently, the project initiated the cryopreservation of reproductive material (sperm, blastula cells). Under the EMB leadership, sperm samples of many carp breeders in Germany will soon be incorporated to the cryobank.

\subsubsection{European cryobanks for farmed species}

Among the fist in Europe, cryobanking of farmed fish sperm was launched in the Czech Republic in 1996 as a part of the National program of conservation and use of farm animal genetic resources. The objective was to keep old less productive breeds as a part of national heritage and a source of genes for contemporary breeding. The Cryobank was established in the Research Institute of Fish Culture and Hydrobiology (RIFCH), part of the nowadays Faculty of Fisheries and Protection of Waters in Vodnany. The cryobank activity is oriented to the maintenance and storage of 6,833 frozen insemination doses of farmed common carp, tench, wels, rainbow- and brown trout, whitefishes and sturgeon, as well as on extending the number of doses. Altogether, sperm samples from 11 breeds of carp, 7 breeds of tench, 3 breeds of wels, 3 breeds of trouts and 2 species of sturgeons are stored. Besides genetic resources, fish sperm cryopreservation is also used for international scientific cooperation and commercial purposes. Until now, the samples were not used for any reconstruction of a breed. In France, it was the development of breeding programs in trout fish farms in the nineties which prompted the need for genetic resource preservation at the production level. First, each breeding farm started to store its own cryopreserved resources thanks to the help of the non-profit professional association SYSAAF (Union of French poultry 
and aquaculture breeders) and the INRA research institute. Almost 10 years later, the CryoAqua bank was set up under the leadership of SYSAAF, INRA and IFREMER: this more secured bank dedicated to French aquatic resources is housed in a bovine genetics cooperative, Evolution (www.evolution-xy.fr), equipped for farmed animal gamete cryopreservation and management. The setting up of CryoAqua was entirely covered by public funding (CCRB/IBiSA 2008), while Evolution provided the lab, storage room and the staff.

Another function of CryoAqua is that this cryobank is the fish and shellfish secondary site of the French National Cryobank (FNCb), a member of the CRB-Anim network since 2012 (national infrastructure connecting reproductive and genomic collections for domestic animals). The National Cryobank was set up in 1999 with three main objectives: preserving genetic diversity, restoring rare genotypes of endangered lines, and monitoring French farmed animal genetic resources. Thanks to the CRB-Anim network, the collections are being enriched and are also intended to be used more broadly, for economic and research purposes.

Today, any private or public organization in France can benefit from CryoAqua service: fresh milt is sent from fish farms to CryoAqua where it is cryopreserved and stored by Evolution's staff. The costs are covered by the collection owner. The straws have a unique number ensuring reliable traceability of the male. Today, CryoAqua houses resources from 9 breeding companies, 2 research institutes and the FNCb, with up to 12 species and lines from fish to molluscs, stored mainly as sperm. As for the Czech bank, CryoAqua is benefiting from the research input via INRA and IFREMER institutes. A specificity of the aquatic collections at CryoAqua is the very strict sanitary regulation: farms or research institutes should obtain a disease-free status before they are allowed to send any sample to CryoAqua. As a consequence, many collections 
without this status are at risk to be lost. A strictly controlled quarantine system of the live fish prior to sperm or cell collection is one mean currently set up to circumvent this limitation, although it increases a lot the cost of the cryobanking procedure.

A cryobank for common carp in Szarvas, Hungary, is managed by the National Agricultural Research and Innovation Centre, Research Institute for Fisheries and Aquaculture (NAIK HAKI, Dr Jeney). The cryobank was created in 2005 in order to serve as a backup to the live common carp gene bank. Originally it was created from sperm samples of 15 Hungarian and 8 foreign carp varieties and 2 more were added in 2007. The basic policy was to cryopreserve 40 straws from 10 males of each variety. Some compromises in the numbers had to be made as the right male number was not always available. The research department of Aquaculture at Szent Istvan University in Gödöllö cooperated with HAKI in the creation of the cryobank for the freezing procedure and random analysis of the sample quality. In May, 2013, stored sperm samples were used to refresh the gene pool of one of the varieties.

\subsubsection{European cryobanks for model species:}

The European Zebrafish Resource centre (EZRC, http://www.ezrc.kit.edu/index.php) was officially opened in July 2012 at the Karlsruhe Institute of Technology (KIT, Germany), to provide permanent repository for zebrafish lines from European researchers and to provide access to those lines for the research community. In the EZRC, zebrafish stocks are maintained mostly as frozen sperm, and when a frozen line is requested, embryos are produced by in vitro fertilization and shipped to the customer. The EZRC could therefore be considered as a cryobank whose service starts from receiving the breeders and ends up with the providing of embryos sired by the frozenthawed sperm. The costs are partly covered by the customer. Because this service is at 
the heart of research, one limitation to this open access centre is that the original provider must agree to make the strain freely available to the whole community for noncommercial purposes. Any commercial licensing is negotiated directly between the recipient and the provider.

To add up to this open service, some laboratories are in the process of developing local cryobanking to secure their newly made transgenic lines (before they feel ready to release them to the scientific community). The difficulty is that gametes from model species (especially zebrafish and medaka) are more difficult to obtain than naturally fertilized embryos, and cryopreservation and in vitro fertilization requires some experience and high quality breeders that are not always available in every research lab (see 2.3 subsection). We believe that such cryobanking should be centralized at a national or regional scale, so that the expertise can be shared between actors, and the equipment and storage costs reduced.

\subsubsection{European cryobanks for research}

Beyond all the above-described banks, it is well known that almost every fish research institute has its own cryobank, very often reduced to few liquid nitrogen tanks. These banks often house the breeds and lines developed by the research groups within one department. Some of these banks can also develop some biodiversity conservation purpose, such as the bank at the Department of Gamete and Embryo Biology in Olsztyn (PL) where wild whitefish or farmed carp strains are cryopreserved.

These banks are the most difficult to track because of course, the intrinsic purpose of these banks is to provide a local service. It is usually run by the researcher themselves, with very variable traceability systems and security systems. One work package of the 
H2020 AquaExcel project (http://www.aquaexcel.eu/) is to establish a network of these scattered cryobanks, to standardize the cryobanking pipeline, and to enlarge the availability of the resources to a broader research community.

\subsection{Cryobanking in USA}

The following summary provides a short overview of cryobanking with examples of various activities. It is not intended to be a comprehensive listing of efforts or facilities in the United States. At present, there is no formal central or national planning authority in the US for germplasm repositories of aquatic species. A broad array of cryopreservation activities have taken place over the past six decades across the country with earliest efforts relating to research of techniques, mostly in salmonids. As such, some collections were informally accrued by researchers using a wide variety of containers and labelling methods, and using diverse cryopreservation protocols. For example, the Aquatic Germplasm and Genetic Resources Center at Louisiana State University Agricultural Center in Baton Rouge, Louisiana, has an inventory of around 65,000 French straws from a wide range of aquatic species. These samples are utilized as a research resource for various studies and projects rather than as a germplasm repository per se.

Over the years, with the establishment of working cryopreseration techniques, emphasis broadened to applications directed at repository development. These included conservation efforts with imperilled species such as chinook salmon, Oncorhynchus tshawytscha and rainbow trout, O. mykiss (Cloud et al., 2011; Harvey et al., 1998), razorback sucker, Xyrauchen texanus (Tiersch et al., 1998), Colorado pikeminnow, Ptychocheilus lucius (Tiersch et al., 2004), and pallid sturgeon, Scaphirhynchus albus (Wayman, 2011). Work with threatened or endangered species has continued with 
support of the US Fish and Wildlife Service and a repository exists at the USFWS Fish Technology Center in Warms Springs, Georgia, largely for pallid sturgeon, but including sperm from salamanders, and sperm and glochidia from freshwater mussels (Wayman, 2011). This collection currently comprises around 26,000 straws (W. Wayman, personal communication).

Another main thrust has been in forming repositories for biomedical research model fishes such as zebrafish (Varga and Westerfield, 2011), and Xiphophorus species (Walter, 2011). This work has been supported largely by the US National Institutes of Health (NIH), and in April 2007, the National Center for Research Resources of the NIH held a meeting entitled Achieving High Throughput Repositories for Biomedical Germplasm Preservation Workshop in which a large-scale overview was developed for current status and needs for development of germplasm resources for biomedical model species (Rall et al., 2011). The final report is available at: www.esibethesda.com/ncrrworkshops/Biomedical/index.aspx. Programmatic development has proceeded in the past few years at the Zebrafish International Resource Center (ZIRC) housed at the University of Oregon in Eugene, Oregon (Varga and Westerfield, 2011). Currently the ZIRC holds the largest biomedical collection in the US with around 60,000 samples from zebrafish representing some 9,000 lines and 26,000 characterized single alleles. To exclude redundancies, a curator-approved name must be established with the Zebrafish Model Organism Database called ZFIN (www.zfin.org). A similar, but smaller repository is being developed for live-bearing fishes held at the Xiphophorus Genetic Stock Center (XGSC) housed at Texas State University in San Marcos, Texas (http://www.xiphophorus.txstate.edu/).

A major national-level advance for aquatic germplasm resources came in 1990 when national legislation was passed that provided the US Department of Agriculture 
(USDA) with a mandate to conserve animal genetic resources (Blackburn, 2011). This legislation provided support for public and private sector initiatives to address conservation of genetic resources (National Research Council, 1993). In 1999, the USDA formed the National Animal Germplasm Program (NAGP) housed in Ft. Collins, Colorado (http://nrrc.ars.usda.gov/A-GRIN/main_webpage/ars?record_source=US). The NAGP is patterned after the well-established USDA National Plant Germplasm System, and has essentially unlimited storage capabilities available based on current national usages of aquatic germplasm. The NAGP is organized around permanent species committees for beef and dairy cattle, swine, goats and sheep, poultry, and aquatic species. The Aquatic Species Committee brings together members from universities, industry, and federal agencies, and is responsible for providing an interface for parties that wish to place material into the NAGP collection or to remove it. The current inventory is maintained in a database that can be viewed at: www.arsgrin.gov:8080/j2ee/nagppub/jsp/nagp/drilldown2.jsp. At present the core collection at NAGP has an inventory of 32,500 samples from around 3,000 individual animals representing major groupings of freshwater and marine fishes, and marine invertebrates. Aquatic species comprise $4.4 \%$ of the entire NAGP collection based on number of samples, but comprise $15 \%$ of the entire collection based on number of individuals. This program, database, its collection, and core capabilities are a tremendous resource for aquatic germplasm conservation in the United States, and has been developing relationships with other countries such as Brazil and Canada. Samples from other collections, such as those mentioned above from the LSU Agricultural Center, USFWS, XGSC, and ZIRC are routinely transferred into the collection at NAGP. Large collections such as those from the Nez Perce tribe, University of Idaho and Washington State University (some 50,000 samples) of chinook salmon and rainbow trout (also 
mentioned above, Cloud et al., 2011) have been transferred to NAGP because resources became unavailable for archival storage at the facilities that performed the original collections. These samples are being catalogued into the database for inclusion in the core collection (H. Blackburn, personal communication). The NAGP can provide a useful model for aquatic species in general for the development of an integrated repository system that incorporates a single or a few well-equipped, experienced central facilities that carry out most of the cryopreservation work using samples or broodstock sent to the facility (Caffey and Tiersch, 2011). Other facilities can serve as satellite repositories to protect backup samples, or as user endpoints for the samples, such as in working hatcheries.

Overall, application of cryopreservation and development of cryobanking for fishes or other aquatic species constitutes a balancing act of attempting to generalize observations into basic principles while recognizing the considerable diversity that exists across these organisms. To address this, the Aquatic Species Committee of the NAGP has employed the following concepts: i) be aware of the differences among entities such as species and user groups; ii) focus on the commonalities across groups and technologies; iii) generalize technology development to the extent possible; iv) target broad application of findings; v) work to reduce barriers to communication and integration across communities (e.g., species, commodity groups, or private and public sectors), and vi) work to establish standardization and harmonization in protocols, terminology, and reporting in the aquatic species cryopreservation literature. Future expansion of cryobanking in the US will likely rest upon advances in high-throughput cryopreservation and commercial-scale application (Hu and Tiersch, 2011; Tiersch, 2011). 


\subsection{Cryobanking in Brazil}

Brazil contains the largest number of hydrographic basins, the largest amount of freshwater available in the world and more than $8,000 \mathrm{~km}$ of coastal regions.

Consequently, Brazil holds the incredible number of 885 marine species and more than 2,100 freshwater species (Buckup and Menezes, 2003), corresponding to almost $21 \%$ of the total number of fish species in the world (Reis et al., 2003), and probably higher due to the large diversity and a considerable number of hydrographic basins that has not yet been studied (Agostinho et al., 2005).

Due to environmental changes mostly caused by human activities such as hydroelectric dams, pollution and overfishing, many fish species and especially those that migrate during the spawning season, are set as endangered. The use of sperm cryobanking could be an alternative to protect this species from extinction by preserving genetic diversity. Many Brazilian fish species have been subjected to sperm cryopreservation studies mainly during the past decade, and these studies have been compiled in recent reviews (Godinho and Viveiros, 2011; Viveiros et al., 2014). However, data on post-thaw sperm quality are highly heterogeneous even for the same species; some reports are incomplete and, given that only positive results are usually published, the true variability of results remains unknown (Viveiros, 2005). Thus, development of reliable cryopreservation protocols for fish sperm are often performed on a species-by-species basis and it differs from one region to another.

In Brazil, the routine use of sperm cryobanks in hatchery production is very limited, if present, but for conservational purposes it is a feasible alternative. The Brazilian Agriculture Research Corporation (EMBRAPA) is in charge of holding germplasm banks of different species of plants, animals and microorganisms of the whole country. The Unit of Pantanal, in the city of Corumbá, holds a sperm cryobank of Piaractus 
mesopotamicus, Salminus brasiliensis, Brycon hilarii, Pseudoplatystoma corruscans and Pseudoplatystoma reticulatum, from the rivers Taquari and Miranda (Resende and Marques, 2009). Since 2012, the Unit of Fisheries and Fish Culture, in the city of Palmas, is organizing a DNA cryobank in order to allow identification and conservation of fish species native to Araguaia-Tocantins basin. This bank stores DNA samples from 68 Amazonian fish species, including some important commercial species such as Colossoma macropomum, Brycon amazonicus, Piaractus brachypomus and Arapaima gigas (Barroso et al., 2013). Finally, the Unit of Tabuleiros Costeiros, in the city of Aracajú, holds DNA and sperm cryobanks of C. macropomum (Dr. A.N. Maria, personal communication).

Besides EMBRAPA, there are some cryobanks at Institutes and Universities in Brazil. At the Institute Chico Mendes for Biodiversity Conservation (CEPTA/ICMBio), in the city of Pirassununga, sperm of Brycon orbignyanus, Brycon vermelha, $P$. mesopotamicus, among other species, are stored for both conservational and restocking purposes (Dr J.A. Senhorini, personal communication). Among the Universities, just to name a few, UFLA, in the city of Lavras, holds sperm cryobanks of Brycon insignis, $B$. orbignyanus, Prochilodus lineatus, Steindachneridion parahybae, S. brasiliensis, among other species, and UEM in the city of Maringá holds samples of B. orbignyanus, Leporinus sp, Leporinus elongates, P. lineatus, P. mesopotamicus, Pseudoplatystoma reticularum, Salminus brasiliensis, Schizodon spp, among other species (Dr. R.P. Ribeiro, personal communication), for both research and restocking purposes.

\subsection{Cryobanking in Australia and New Zealand}

In both New Zealand and Australia there are only a handful of cryobanks for aquatic species and cell types. The banks have been created and maintained for a variety of 
purposes from fundamental to applied research, and from conservation to commercial applications.

\subsubsection{Cryobanks of molluscs}

Cryopreservation is potentially a powerful tool for selective breeding and hatchery production of molluscs (Adams et al., 2011, 2015; Tiersch et al., 2007). It can enable breeders to have complete control over parental crosses and provide a resource for breeders to return to when breeding programme objectives change. In hatchery production, it can reduce broodstock conditioning costs and allow excess gametes from a spawning to be stored for later use. The benchmarks for incorporating cryopreservation in selective breeding and in hatchery production differ. For hatchery production, $\sim 350$ million -1 billion early D-stage larvae are required for each commercial batch. However, selective breeding requires only 100 000 larvae per family. Cryopreserving mollusc gametes and early embryos can also be useful in ecotoxicology for carrying out direct toxicity assessments outside the natural spawning season (Adams et al., 2015).

Cryopreservation methods have been developed for the sperm of New Zealand's commercially important shellfish species including the greenshell ${ }^{\mathrm{TM}}$ mussel (Perna canaliculus), Pacific oyster (Crassostrea gigas) and abalone (paua; Haliotis iris) (Adams et al., 2008, 2011, 2015; Smith et al., 2012). The Cawthron Institute runs selective breeding programs for greenshell ${ }^{\mathrm{TM}}$ mussel and Pacific oyster for the New Zealand aquaculture industry. As part of these programs, sperm collected from individuals used to make family crosses in a breeding run is banked. Methods have also been developed for cryopreserving Pacific oyster oocytes and for larvae of greenshell ${ }^{\mathrm{TM}}$ mussels and Pacific oyster (Paredes et al., 2012, 2013; Tervit et al., 2005). These 
methods have not yet been incorporated in either selective breeding or hatchery production and further research is needed to improve the reliability of these methods for both purposes. The current methods for sperm are also being continually refined and methods for emerging species such as geoduck (Panopea zelandica) are being developed (Adams et al., 2012).

In Australia, gametes and embryos of the blue mussel, Mytilus galloprovincialis, are banked for out of season commercial production (Xiaoxu Li, SARDI, personal communication) but presently there is no banking for selective breeding ( $\mathrm{Liu}$ and $\mathrm{Li}$, 2015; Paredes et al., 2013).

\subsubsection{Microalgae cryobanks}

In New Zealand, the Cawthron Institute maintains the Cawthron Institute Culture Collection of Microalgae (CICCM) - a collection of over 400 strains of freshwater and marine microalgae as well as cyanobacteria collected from New Zealand waters (Krystyna Ponikla, Cawthron Institute, personal communication). Over 250 of these strains are held cryopreserved in liquid nitrogen. The collection includes a number of unique species and strains and underpins applied and fundamental research including: characterisation of algal toxin producers and their toxins, phytoplankton monitoring, validation of molecular-based detection tools, as well as research for bioactive and novel compounds (Rhodes et al., 2006; Woods et al., 2008).

In Australia, CSIRO maintains the Australian National Algae Culture Collection. Although the collection contains over 1000 strains of microalgae, almost all are maintained in liquid/agar cultures with only a few, mainly thraustochytrids, maintained at $-80^{\circ} \mathrm{C}$ (Ian Jameson, CSIRO National Facilities and Collections, personal communication). The University of Queensland has its own cryobank of microalgae 
containing over 200 strains (Ben Hankamer, University of Queensland, personal communication) (Bui et al., 2013) and is used for algal biotechnology research including sustainable production of biodiesel, protein-rich animal feed and other high value products from microalgae (http://www.schenklab.com/research-groups/algaebiotechnology/).

\subsubsection{Cryobanking of fish}

Sperm cryobanks are maintained in some fish hatcheries as part of their selective breeding programmes. New Zealand King Salmon has a selective breeding programme for the King salmon (also known as chinook salmon; Oncorhynchus tshawytscha) that it farms. It maintains a cryobank of sperm dating back to 1996 frozen using a method developed in house (Jon Bailey, New Zealand King Salmon; Jane Symmonds, NIWA, personal communication). Each year New Zealand King Salmon selects around 10 males with different traits, often unusual, or low incidence ones to add to its bank. This year they will trial a different method using cryogenetics' square packs.

In Australia, the CSIRO and Salmon Enterprises of Tasmania Pty Limited (SALTAS) run a joint project to enhance selective breeding of Atlantic salmon (Salmo salar) for the Australian salmon farming industry. (http://www.csiro.au/en/Research/AF/Areas/Aquaculture/Premium-breeds/breedingsalmon/ ). This program also cryopreserves milt (Peter Kube, CSIRO, personal communication).

\subsubsection{Cryobanking of other species}

With increasing pressure from climate change, habitat loss, over fishing and anthropogenic inputs, many aquatic species are now threatened or endangered. In 
Australia and New Zealand, cryopreservation research is being carried out on germplasm from a range of species from frogs to elasmobranchs (Jonathan Daly, The Australian Frozen Zoo; Rebecca Hobbs, Taronga Conservation Society Australia, personal communication) (Browne et al., 2002).

The Taronga Conservation Society Australia maintains the Taronga CryoReserve - a bank that stores germplasm from "at risk" species (Rebecca Hobbs, Taronga Conservation Society Australia, personal communication). At this time, the bank maintains germplasm from a number of coral species from the Great Barrier Reef (Hagedorn and Spindler, 2014; Hagedorn et al., 2012) as well as from Dugong (Dugong dugon) and these are the only aquatic species in the bank. The CryoReserve also participates in projects investigating sperm cryobiology of other "at risk" species.

\section{Concluding remarks}

Cryopreservation of germ cells has a huge potential, especially concerning sperm research that has been quite developed. Research on germplasm cryobanking of aquatic species embrace diverse cell types including sperm, oocytes, somatic cells, spermatogonia and primordial germ cells, besides cryopreservation of embryos and larvae, both successfully developed in invertebrate species. In fish species, sperm cryopreservation has been quite developed mainly due to the handicaps presented by other cell types such as oocytes or embryos, which needs the optimization of protocols for both cryopreservation and oocyte in vitro maturation. Recent studies have arisen on cryopreservation of primordial germ cells as an alternative for the cryopreservation of both paternal and maternal genomes. However, more work needs to be carried out in the development of reproductive biotechnological tools, such as transplantation, to restore an individual or a species. Cryopreservation of fish tissues, especially fin pieces, can 
easily be considered for cryobanking with some minor technical adjustments. However, the regeneration methods necessary to recover the fish are still at the level of research development: although the nuclear transfer technology is globally mastered in fish, the reprogramming of the somatic gene expression into an embryonic pattern has to be extensively studied in order to yield higher development rates. The limitations to interspecific nuclear transfer have to be explored as well. Last, reprogramming of somatic cells into primordial germ cells is an open field with still very little data in fish. Cryopreservation methods are developed for various purposes: to assist reproduction in aquaculture, to be applied in selective breeding programs or to be applied in species conservation actions. In the recent years, the aquaculture industry has been suffering technological advancements accompanied by an increased interest on sperm cryopreservation. However, the application of cryopreservation methods as part of the greater fish farming industry is still limited in comparison to the cryopreservation industry serving domestic livestock farming. This is mainly due to the absence of standardized methods for fish sperm cryopreservation. To solve this issue, cryobiologists are doing a huge effort to reduce ambiguities in reporting cryopreservation results, but more specific guidelines might be necessary for aquatic species to establish protocols universally accepted. Germplasm cryobanking of aquatic species has significant potential, but to optimize the management of these banks a multidisciplinary team with skills in genetics, reproductive physiology, cryobiology and data administration is required. Thus, careful planning and cooperation among various disciplines involved in a given conservation program, and a close cooperation of cryobiologists with other representatives of science and management, is a key factor for the successful use of cryopreservation. 


\section{Acknowledgements}

The authors thank Dr E. Kopeika, Dr M. Flajšhans, Dr B. Dzyuba, Dr S. Rakers, Dr A. Ciereszko and Dr R. Geisler for their help in tracking the history of the European cryobanks. This work was partially funded by COST Office (Food and Agriculture COST Action FA1205: AQUAGAMETE) and projects KLING 31-03-05-FEP-73, CRIOBIV 31-03-05-FEP-59, REPLING 31-03-05-FEP-69 financed by Portuguese PROMAR program; grants AGL2011-27787 and AGL2014-53167-C3-3-R from the Spanish Ministry of Economy and Competitiveness; NKFIH grant K109847, 9878/2015/FEKUT of the Ministry of Human Resources of Hungary awarded to Szent István University; French program "Investissements d'Avenir" ANR-11-INBS-0003 (CRB-Anim 2013-2019), and Creche (Ofimer 136/08/C) and CRB anim (ANR-11INBS-0003); National Institutes of Health of U.S. (5R24OD010441); New Zealand Ministry of Business, Innovation and Employment (CAWX1315); Brazilian funding agencies FAPEMIG and CNPq; and FCT postdoctoral fellowship (SFRH/BPD/48520/2008) funded by Portuguese National Funds (MEC).

\section{References}

Acosta-Salmón, H., Jerry, D.R., Southgate, P.C., 2007. Effects of cryoprotectant agents and freezing protocol on motility of black-lip pearl oyster (Pinctada margaritifera L.) spermatozoa. Cryobiology. 54, 13-18.

Adams, S.L., Hessianand, P.A.V., Mladenov, P.V., 2004. Cryopreservation of sea urchin (Evechinus chloroticus) sperm. Cryoletters. 25, 287-299.

Adams, S.L., Hessian, P.A., Mladenov, P.V., 2006. The potential for cryopreserving larvae of the sea urchin, Evechinus chloroticus. Cryobiology. 52, 139-145. 
Adams, S.L., Salinas-Flores, L., Lim, M.H., 2013. Diet conditioning of Pacific oyster, Crassostrea gigas, broodstock to improve oocyte cryopreservation success. J. Shellfish Res. 32, 391-399.

Adams, S.L., Smith, J.F., Taylor, J., McGowan, L., Tervit, H.R., 2015.

Cryopreservation of Greenshell Mussel ${ }^{\mathrm{TM}}$ (Perna canaliculus) Sperm. In: Wolkers, W.F., Oldenhof, H. (Eds.), Cryopreservation and Freeze-Drying Protocols, Methods in Molecular Biology vol 1257. Springer Science + Business, New York, pp. 329-336.

Adams, S.L., Smith, J.F., Roberts, R.D., Janke, A.R., King, N.G., Tervit, H.R., Webb, S.C., 2008. Application of sperm cryopreservation in selective breeding of the Pacific oyster, Crassostrea gigas (Thunberg). Aquac. Res. 39, 1434-1442. Adams, S.L., Smith, J.F., Tervit, H.R., Gale, S.L., McGowan, L.T., Morrish, J.R., Watts, E., Taylor, J., 2012. Cryopreservation and fertility of geoduck (Panopea zelandica) sperm and oocytes. Cryobiology. 65, 344-345.

Adams, S.L., J.F., S., Tervit, H.R., McGowan, L.T., Roberts, R.D., Janke, A.R., King, N.G., Gale, S.L., Webb, S.C., 2011. Cryopreservation of Molluscan Sperm: Pacific Oyster, Green-lipped Mussel, and Paua Abalone. In: Tiersch, T.R., Green, C.C. (Eds.), Cryopreservation in Aquatic Species, 2nd Ed. World Aquaculture Society, Baton Rouge, Louisiana, pp. 562-573.

Agostinho, A.A., Thomaz, S.M., Gomes, L.C., 2005. Conservation of the biodiversity of Brazil's inland waters. Conserv. Biol. 19, 646-652.

Ahammad, M.M., Bhattacharyya, D., Jana, B.B., 2003. Stage-dependent hatching responses of rohu (Labeo rohita) embryos to different concentrations of cryoprotectants and temperatures. Cryobiology. 46, 2-16. 
Akimenko, M.-A., Marí-Beffa, M., Becerra, J., Géraudie, J., 2003. Old questions, new tools, and some answers to the mystery of fin regeneration. Dev. Dynam. 226, 190-201.

Anchordoguy, T., Crowe, J.H., Griffin, F.J., Clark Jr, W.H., 1988. Cryopreservation of sperm from the marine shrimp Sicyonia ingentis. Cryobiology. 25, 238-243.

Anil, S., 2013. Development of in vitro culture and cryopreservation protocol for zebrafish (Danio rerio) ovarian tissue fragments, $\mathrm{PhD}$ Thesis. University of Bedfordshire, United Kingdom.

Anil, S., Zampolla, T., Zhang, T., 2011. Development of in vitro culture method for zebrafish ovarian tissue fragment. Cryobiology. 63, 311-312.

Aoki, K., Okamoto, M., Tatsumi, K., Ishikawa, Y., 1997. Cryopreservation of medaka spermatozoa. Zool. Sci. 14, 641-644.

Aramli, M.S., Golshahi, K., Nazari, R.M., Aramli, S., 2015. Effect of freezing rate on motility, adenosine triphosphate content and fertilizability in beluga sturgeon (Huso huso) spermatozoa. Cryobiology. 70, 170-174.

Asturiano, J., Marco-Jiménez, F., Peñaranda, D., Garzón, D., Pérez, L., Vicente, J., Jover, M., 2007. Effect of sperm cryopreservation on the European eel sperm viability and spermatozoa morphology. Reprod. Domest. Anim. 42, 162-166.

Asturiano, J.F., Pérez, L., Marco-Jiménez, F., Olivares, L., Vicente, J.S., Jover, M., 2003. Media and methods for the cryopreservation of European eel (Anguilla anguilla) sperm. Fish Physiol. Biochem. 28, 501-502.

Babiak, I., Bolla, S., Ottesen, O., 2008. Suitable methods for cryopreservation of semen from Atlantic halibut, Hippoglossus hippoglossus L. Aquacult. Int. 16, 561-572.

Babiak, I., Ottesen, O., Rudolfsen, G., Johnsen, S., 2006a. Chilled storage of semen from Atlantic halibut, Hippoglossus hippoglossus L. II: Effect of spermiation 
advancement, catheterization of semen, and production-scale application.

Theriogenology. 66, 2036-2046.

Babiak, I., Ottesen, O., Rudolfsen, G., Johnsen, S., 2006b. Chilled storage of semen from Atlantic halibut, Hippoglossus hippoglossus L.: I: Optimizing the protocol. Theriogenology. 66, 2025-2035.

Babiak, I., Dobosz, S., Goryczko, K., Kuzminski, H., Brzuzan, P., Ciesielski, S., 2002. Androgenesis in rainbow trout using cryopreserved spermatozoa: the effect of processing and biological factors. Theriogenology. 57, 1229-1249.

Bail, P.-Y., Depince, A., Chenais, N., Mahe, S., Maisse, G., Labbe, C., 2010.

Optimization of somatic cell injection in the perspective of nuclear transfer in goldfish. BMC Dev. Biol. 10, 64.

Barnes, D.W., Parton, A., Tomana, M., Hwang, J.-H., Czechanski, A., Fan, L., Collodi, P., 2008. Stem cells from cartilaginous and bony fish. In: Dr. Jennie, P.M. (Ed.), Methods in Cell Biology. Academic Press, pp. 343-367.

Barroso, A.S., Silva, L.R., Barros, V.M., Oliveira, A.S., Alves, M.S.S., Varela, E.S., Hashimoto, D.T, Alves, A.L., 2013. Implantação do banco de DNA de peixes da bacia Araguaia-Tocantins: aplicações na taxonomia, produção e conservação de recursos genéticos. Rev. Integralização Universitária - RIU 7, 173-180.

Available at

http://ainfo.cnptia.embrapa.br/digital/bitstream/item/92822/1/p173.pdf

Basavaraja, N., Hegde, S.N., 2004. Cryopreservation of the endangered mahseer (Tor khudree) spermatozoa: I. Effect of extender composition, cryoprotectants, dilution ratio, and storage period on post-thaw viability. Cryobiology. 49, 149156. 
Beirão, J., Cabrita, E., Pérez-Cerezales, S., Martínez-Páramo, S., Herráez, M.P., 2011. Effect of cryopreservation on fish sperm subpopulations. Cryobiology. 62, 2231.

Benson, E.E., Betsou, F., Fuller, B.J., Harding, K., Kofanova, O., 2013. Translating cryobiology principles into trans-disciplinary storage guidelines for biorepositories and biobanks: a concept paper. Cryoletters. 34, 277-312.

Bercsényi, M., Magyary, I., Urbányi, B., Orbán, L., Horváth, L., 1998. Hatching out goldfish from common carp eggs: interspecific androgenesis between two cyprinid species. Genome. 41, 573-579.

Bernáth, G., Bokor, Z., Kása, E., Várkonyi, L., Hegyi, Á., Kollár, T., Urbányi, B., Żarski, D., Radóczi Ifj, J., Horváth, Á., 2015. Comparison of two different methods in the cryopreservation of Eurasian perch (Perca fluviatilis) sperm. Cryobiology. 70, 76-78.

Biddle, A., Simeoni, I., Gurdon, J.B., 2009. Xenopus oocytes reactivate muscle gene transcription in transplanted somatic nuclei independently of myogenic factors. Development (Cambridge, England). 136, 2695-2703.

Biran, A., Meshorer, E., 2012. Concise review: chromatin and genome organization in reprogramming. Stem cells (Dayton, Ohio). 30, 1793-1799.

Blackburn, H.D., 2011. The USDA national animal germplasm program and the aquatic species collection. In: Tiersch, T.R., Green, C.C. (Eds.), Cryopreservation in Aquatic Species, 2nd Ed. World Aquaculture Society, Baton Rouge, Louisiana, pp. 774-779.

Bokor, Z., Urbányi, B., Horváth, L., Horváth, Á., 2010. Commercial-scale cryopreservation of wels catfish (Silurus glanis) semen. Aquac. Res. 41, 15491551. 
Bolla, S., Holmefjord, I., Refstie, T., 1987. Cryogenic preservation of Atlantic halibut sperm. Aquaculture. 65, 371-374.

Browne, R.K., Clulow, J., Mahony, M., 2002. The short-term storage and cryopreservation of spermatozoa from hylid and myobatrachid frogs. Cryoletters. 23, 129-136.

Buckup, P.A., Menezes, N.A., 2003. Catalogo de peixes marinhos e de água doce do Brasil, 2nd ed. Museu Nacional, Rio de Janeiro. Available at http://www.mnrj.ufrj.br/catalogolo/.

Bui, T.V.L., Ross, I.L., Jakob, G., Hankamer, B., 2013. Impact of procedural steps and cryopreservation agents in the cryopreservation of chlorophyte microalgae. PLoS ONE. 8, e78668.

Butts, I.A.E., Litvak, M.K., Kaspar, V., Trippel, E.A., 2010. Cryopreservation of Atlantic cod Gadus morhua L. spermatozoa: Effects of extender composition and freezing rate on sperm motility, velocity and morphology. Cryobiology. 61, 174-181.

Cabrita, E., Robles, V., Herráez, M.P. (Eds.), 2008. Methods in Reproductive Aquaculture: Marine and Freshwater Species. CRCPress, Boca Raton, FL, USA, 549 pp. ISBN: 13:978-0-8493-8053-2.

Cabrita, E., Robles, V., Alvarez, R., Herraez, M.P., 2001. Cryopreservation of rainbow trout sperm in large volume straws: application to large scale fertilization. Aquaculture. 201, 301-314.

Cabrita, E., Engrola, S., Conceição, L.E.C., Pousão-Ferreira, P., Dinis, M.T., 2009. Successful cryopreservation of sperm from sex-reversed dusky grouper, Epinephelus marginatus. Aquaculture. 287, 152-157. 
Cabrita, E., Robles, V., Chereguini, O., de Paz, P., Anel, L., Herraez, M.P., 2003.

Dimethyl sulfoxide influx in turbot embryos exposed to a vitrification protocol. Theriogenology. 60, 463-473.

Cabrita, E., Robles, V., Cunado, S., Wallace, J.C., Sarasquete, C., Herraez, M.P., 2005. Evaluation of gilthead sea bream, Sparus aurata, sperm quality after cryopreservation in $5 \mathrm{ml}$ macrotubes. Cryobiology. 50, 273-284.

Cabrita, E., Martínez-Páramo, S., Gavaia, P.J., Riesco, M.F., Valcarce, D.G., Sarasquete, C., Herráez, M.P., Robles, V., 2014. Factors enhancing fish sperm quality and emerging tools for sperm analysis. Aquaculture. 432, 389-401.

Caffey, R.H., Tiersch, T.R., 2011. Economics and marketing of cryopreserved fish sperm. In: Tiersch, T.R., Green, C.C. (Eds.), Cryopreservation in Aquatic Species, 2nd Ed. World Aquaculture Society, Baton Rouge, Louisiana, pp. 896916.

Cai, H., Xia, X., Wang, L., Liu, Y., He, Z., Guo, Q., Xu, C., 2013. In vitro and in vivo differentiation of induced pluripotent stem cells into male germ cells. Biochem. Bioph. Res. Co. 433, 286-291.

Cartón-García, F., Riesco, M.F., Cabrita, E., Herráez, M.P., Robles, V., 2013. Quantification of lesions in nuclear and mitochondrial genes of Sparus aurata cryopreserved sperm. Aquaculture. 402-403, 106-112.

Ciereszko, A., Dabrowski, K., Froschauer, J., Wolfe, T.D., 2006. Cryopreservation of semen from lake sturgeon. T. Am. Fish. Soc. 135, 232-240.

Ciereszko, A., Dietrich, G.J., Nynca, J., Dobosz, S., Zalewski, T., 2014.

Cryopreservation of rainbow trout semen using a glucose-methanol extender. Aquaculture. 420-421, 275-281. 
Cloud, J.G., Miller, W.H., Levanduski, M.J., 1990. Cryopreservation of sperm as a means to store salmonid germ plasm and to transfer genes from wild fish to hatchery populations. Prog. Fish. Cult. 52, 51-53.

Cloud, J.G., A., R., Wheeler, P.A., Kucera, P.A., Thorgaard, G.H., 2011. The Northwest salmonid germplasm repository. In: Tiersch, T.R., Green, C.C. (Eds.), Cryopreservation in Aquatic Species, 2nd Ed. World Aquaculture Society, Baton Rouge, Louisiana, pp. 789-793.

Collodi, P., Kamei, Y., Ernst, T., Miranda, C., Buhler, D.R., Barnes, D.W., 1992.

Culture of cells from zebrafish (Brachydanio rerio) embryo and adult tissues. Cell Biol. Toxicol. 8, 43-61.

Crivelli, A.J., Poizat, G., Berrebi, P., Jesensek, D., Rubin, J.-F., 2000. Conservation biology applied to fish: The example of a project for rehabilitating the marble trout (Salmo marmoratus) in Slovenia. Cybium. 24, 211-230.

Chao, N.-H., Chiang, C.-P., Hsu, H.-W., Tsai, C.-T., Lin, T.-T., 1994. Toxicity tolerance of oyster embryos to selected cryoprotectants. Aquat. Living Resour. 7, 99-104.

Chen, S.L., Tian, Y.S., 2005. Cryopreservation of flounder (Paralichthys olivaceus) embryos by vitrification. Theriogenology. 63, 1207-1219.

Chenais, N., Depince, A., Le Bail, P.-Y., Labbe, C., 2014. Fin cell cryopreservation and fish reconstruction by nuclear transfer stand as promising technologies for preservation of finfish genetic resources. Aquacult. Int. 22, 63-76.

Chereguini, O., García de la Banda, I., Herrera, M., Martinez, C., De la Hera, M., 2003. Cryopreservation of turbot Scophthalmus maximus (L.) sperm: fertilization and hatching rates. Aquac. Res. 34, 739-747. 
Choi, Y.H., Chang, Y.J., 2003. The influence of cooling rate, developmental stage, and the addition of sugar on the cryopreservation of larvae of the pearl oyster Pinctada fucata martensii. Cryobiology. 46, 190-193.

Choi, Y.H., Chang, Y.J., 2014. Influences of developmental stages, protective additives and concentrations of cryoprotective agents on the cryopreservation of Pacific oyster (Crassostrea gigas) larvae. Cryoletters. 35, 495-500.

Daly, J., Tiersch, T.R., 2011. Flow cytometry for the assessment of sperm quality in aquatic species. In: Tiersch, T.R., Green, C. (Eds.), Cryopreservation in Aquatic Species, 2nd Ed. World Aquaculture Society, Baton Rouge, Louisiana, pp. 201207.

de Carvalho, A.F.S., Ramos, S.E., de Carvalho, T.S.G., de Souza, Y.C.P., Zangeronimo, M.G., Pereira, L.J., Murgas, L.D.S., 2014. Efficacy of fish embryo vitrification protocols in terms of embryo morphology - A systematic review. Cryoletters. $35,361-370$.

Desai, K., Spikings, E., Zhang, T., 2011. Effect of chilling on sox2, sox3 and sox19a gene expression in zebrafish (Danio rerio) embryos. Cryobiology. 63, 96-103.

Di Matteo, O., Langellotti, A.L., Masullo, P., Sansone, G., 2009. Cryopreservation of the Mediterranean mussel (Mytilus galloprovincialis) spermatozoa. Cryobiology. 58, 145-150.

Digmayer, M., 2013. Studies on viability of pacu, Piaractus mesopotamicus (Holmberg, 1887) embryos exposed to $-8{ }^{\circ} \mathrm{C}$ and different cryoprotectant concentrations, PhD Thesis. Maringá State University, Brazil.

Ding, F., Lall, S.P., Li, J., Lei, J., Rommens, M., Milley, J.E., 2011. Cryopreservation of sperm from Atlantic halibut (Hippoglossus hippoglossus, L.) for commercial application. Cryobiology. 63, 56-60. 
Ding, F., Milley, J.E., Rommens, M., Li, J., Lei, J., Lall, S.P., 2012. Effect of hormone implantation on cryopreservation of Atlantic halibut (Hippoglossus hippoglossus L.) sperm. Cryobiology. 65, 51-55.

Ding, F.H., Xiao, Z.Z., Li, J., 2007. Preliminary studies on the vitrification of red sea bream (Pagrus major) embryos. Theriogenology. 68, 702-708.

Dinnyes, A., Urbanyi, B., Baranyai, B., Magyary, I., 1998. Chilling sensitivity of carp (Cyprinus carpio) embryos at different developmental stages in the presence or absence of cryoprotectants: Work in progress. Theriogenology. 50, 1-13.

Dong, Q., Huang, C., Eudeline, B., Tiersch, T.R., 2005. Systematic factor optimization for cryopreservation of shipped sperm samples of diploid Pacific Oysters, Crassostrea gigas. Cryobiology. 51, 176-197.

Dong, Q., Huang, C., Eudeline, B., Allen Jr, S.K., Tiersch, T.R., 2006. Systematic factor optimization for sperm cryopreservation of tetraploid Pacific oysters, Crassostrea gigas. Theriogenology. 66, 387-403.

Draper, B.W., Moens, C.B., 2009. A high-throughput method for zebrafish sperm cryopreservation and in vitro fertilization. Journal of visualized experiments: JOVE. 1395.

Dunham, R.A., 2004. Gynogenesis, androgenesis, cloned populations and nuclear transplantation. In: Dunham, R.A. (Ed.), Aquaculture and fisheries biotechnology: genetic approaches.

Dunn, R.S., McLachlan, J., 1973. Cryopreservation of echinoderm sperm. Canadian journal of zoology. 51, 666-669.

Dziewulska, K., Rzemieniecki, A., Czerniawski, R., Domagała, J., 2011. Post-thawed motility and fertility from Atlantic salmon (Salmo salar L.) sperm frozen with four cryodiluents in straws or pellets. Theriogenology. 76, 300-311. 
Dzyuba, B., Cosson, J., Yamaner, G., Bondarenko, O., Rodina, M., Gela, D., Bondarenko, V., Shaliutina, A., Linhart, O., 2013. Hypotonic treatment prior to freezing improves cryoresistance of common carp (Cyprinus carpio L.) spermatozoa. Cryobiology. 66, 192-194.

Edashige, K., Valdez Jr, D.M., Hara, T., Saida, N., Seki, S., Kasai, M., 2006. Japanese flounder (Paralichthys olivaceus) embryos are difficult to cryopreserve by vitrification. Cryobiology. 53, 96-106.

Effer, B., Figueroa, E., Augsburger, A., Valdebenito, I., 2013. Sperm biology of Merluccius australis: Sperm structure, semen characteristics and effects of $\mathrm{pH}$, temperature and osmolality on sperm motility. Aquaculture. 408-409, 147-151.

Eilertsen, K.J., Power, R.A., Harkins, L.L., Misica, P., 2007. Targeting cellular memory to reprogram the epigenome, restore potential, and improve somatic cell nuclear transfer. Anim. Reprod. Sci. 98, 129-146.

El-Battawy, K.A., Linhart, O., 2009. Preliminary studies on cryopreservation of common tench (Tinca tinca) embryos (work in progress). Reprod. Domest. Anim. 44, 718-723.

Enright, B.P., Jeong, B.S., Yang, X., Tian, X.C., 2003. Epigenetic characteristics of bovine donor cells for nuclear transfer: levels of histone acetylation. Biol Reprod. 69, 1525-1530.

Fabbrocini, A., Lavadera, S.L., Rispoli, S., Sansone, G., 2000. Cryopreservation of Seabream (Sparus aurata) Spermatozoa. Cryobiology. 40, 46-53.

Fauvel, C., Suquet, M., Dreanno, C., Zonno, V., Menu, B., 1998. Cryopreservation of sea bass (Dicentrarchus labrax) spermatozoa in experimental and production simulating conditions. Aquat. Living Resour. 11, 387-394. 
Fauvel, C., Boryshpolets, S., Cosson, J., Wilson Leedy, J.G., Labbé, C., Haffray, P., Suquet, M., 2012. Improvement of chilled seabass sperm conservation using a cell culture medium. J. Appl. Ichthyol. 28, 961-966.

Figueroa, E., Merino, O., Risopatrón, J., Isachenko, V., Sánchez, R., Effer, B., Isachenko, E., Farias, J.G., Valdebenito, I., 2015. Effect of seminal plasma on Atlantic salmon (Salmo salar) sperm vitrification. Theriogenology. 83, 238245.e232.

Fornari, D.C., Ribeiro, R.P., Streit, D.J., Godoy, L.C., Neves, P.R., de Oliveira, D., Sirol, R.N., 2014. Effect of cryoprotectants on the survival of cascudo preto (Rhinelepis aspera) embryos stored at $-8^{\circ} \mathrm{C}$. Zygote. $22,58-63$.

Fraser, D.J., 2008. How well can captive breeding programs conserve biodiversity? A review of salmonids. Evol. Appl. 1, 535-586.

Gaitán-Espitia, J.D., Martínez-Silva, M.A., Borrero, C.E., Ramírez, L., Valencia, J.P., 2013. Cryogenic preservation of sperm from lane snapper (Lutjanus synagris): Testing the effects of extenders and freezing rates on sperm quality. Aquaculture. 384-387, 6-12.

Gaspar-Maia, A., Alajem, A., Meshorer, E., Ramalho-Santos, M., 2011. Open chromatin in pluripotency and reprogramming. Nat. Rev. Mol. Cell Biol. 12, 3647.

Godinho, H.P., Viveiros, A.T.M., 2011. Current status of sperm cryopreservation of Brazilian characiform fishes. In: Tiersch, T.R., Green, C.C. (Eds.), Cryopreservation in Aquatic Species. $2^{\text {nd }}$ edition World Aquaculture Society, Baton Rouge, Louisiana, pp. 875-884. 
Godoy, L.C., Streit Jr, D.P., Zampolla, T., Bos-Mikich, A., Zhang, T., 2013. A study on the vitrification of stage III zebrafish (Danio rerio) ovarian follicles. Cryobiology. 67, 347-354.

Groison, A.-L., Suquet, M., Cosson, J., Mayer, I., Severe, A., Bouquet, J.-M., Geffen, A.J., Utne-Palm, A.C., Kjesbu, O.S., 2010. Sperm motility in European hake, Merluccius merluccius, and characterization of its spermatozoa concentration and volume, spermatocrit, osmolality and $\mathrm{pH}$. Aquaculture. 301, 31-36.

Grunina, A.S., Recoubratsky, A.V., Tsvetkova, L.I., Barmintsev, V.A., 2006. Investigation on dispermic androgenesis in sturgeon fish. The first successful production of androgenetic sturgeons with cryopreserved sperm. Int. J. Refrig. Issue with Special Emphasis on Cryobiology. 29, 379-386.

Guan, M., Rawson, D.M., Zhang, T., 2008. Cryopreservation of zebrafish (Danio rerio) oocytes using improved controlled slow cooling protocols. Cryobiology. 56, 204-208.

Guan, M., Rawson, D.M., Zhang, T., 2010. Cryopreservation of zebrafish (Danio rerio) oocytes by vitrification. Cryoletters. 31, 230-238.

Guerra, S.M., Valcarce, D.G., Cabrita, E., Robles, V., 2013. Analysis of transcripts in gilthead seabream sperm and zebrafish testicular cells: mRNA profile as a predictor of gamete quality. Aquaculture. 406-407, 28-33.

Gwo, J.-C., Wu, C.-Y., Chang, W.-S.P., Cheng, H.-Y., 2003. Evaluation of damage in pacific oyster (Crassostrea gigas) spermatozoa before and after cryopreservation using comet assay. Cryoletters. 24, 171-180.

Gwo, J.C., 1995. Cryopreservation of oyster (Crassostrea gigas) embryos. Theriogenology. 43, 1163-1174. 
Hagedorn, M., Spindler, R., 2014. The reality, use and potential for cryopreservation of coral reefs. In: Holt, W.V., Brown, J.L., Comizzoli, P. (Eds.), Reproductive sciences in animal conservation. Springer New York, pp. 317-329.

Hagedorn, M., Kleinhans, F.W., Wildt, D.E., Rall, W.F., 1997a. Chill sensitivity and cryoprotectant permeability of dechorionated zebrafish embryos, Brachydanio rerio. Cryobiology. 34, 251-263.

Hagedorn, M., Hsu, E.W., Pilatus, U., Wildt, D.E., Rall, W.R., Blackband, S.J., 1996. Magnetic resonance microscopy and spectroscopy reveal kinetics of cryoprotectant permeation in a multicompartmental biological system. P. Natl. Acad. Sci. USA. 93, 7454-7459.

Hagedorn, M., Kleinhans, F.W., Freitas, R., Liu, J., Hsu, E.W., Wildt, D.E., Rall, W.F., 1997b. Water distribution and permeability of zebrafish embryos, Brachydanio rerio. J. Exp. Zool. 278, 356-371.

Hagedorn, M., Lance, S.L., Fonseca, D.M., Kleinhans, F.W., Artimov, D., Fleischer, R., Hoque, A.T., Hamilton, M.B., Pukazhenthi, B.S., 2002. Altering fish embryos with aquaporin-3: an essential step toward successful cryopreservation. Biol. Reprod. 67, 961-966.

Hagedorn, M., van Oppen, M.J.H., Carter, V., Henley, M., Abrego, D., Puill-Stephan, E., Negri, A., Heyward, A., MacFarlane, D., Spindler, R., 2012. First frozen repository for the Great Barrier Reef coral created. Cryobiology. 65, 157-158.

Harvey, B., Ross, C., Greer, D., Carolsfeld, J. (Eds.), 1998. Action before extinction: an international conference on conservation of fish genetic diversity. World Fisheries Trust, Victoria, Canada, 259 pp. 
Hattori, M., Hashimoto, H., Bubenshchikova, E., Wakamatsu, Y., 2011. Nuclear transfer of embryonic cell nuclei to non-enucleated eggs in zebrafish, Danio rerio. Int. J. Biol. Sci. 7, 460-468.

He, Q., Lu, G., Che, K., Zhao, E., Fang, Q., Wang, H., Liu, J., Huang, C., Dong, Q., 2011. Sperm cryopreservation of the endangered red spotted grouper, Epinephelus akaara, with a special emphasis on membrane lipids. Aquaculture. $318,185-190$.

Higaki, S., Mochizuki, K., Baba, H., Akashi, Y., Yamaha, E., Katagiri, S., Takahashi, Y., 2009. Feasibility of cryopreservation of zebrafish (Danio rerio) primordial germ cells by whole embryo freezing. Jpn. J. Vet. Res. 57, 119-128.

Higaki, S., Kawakami, Y., Eto, Y., Yamaha, E., Nagano, M., Katagiri, S., Takada, T., Takahashi, Y., 2013. Cryopreservation of zebrafish (Danio rerio) primordial germ cells by vitrification of yolk-intact and yolk-depleted embryos using various cryoprotectant solutions. Cryobiology. 67, 374-382.

Higaki, S., Eto, Y., Kawakami, Y., Yamaha, E., Kagawa, N., Kuwayama, M., Nagano, M., Katagiri, S., Takahashi, Y., 2010. Production of fertile zebrafish (Danio rerio) possessing germ cells (gametes) originated from primordial germ cells recovered from vitrified embryos. Reproduction. 139, 733-740.

Hong, N., Li, Z., Hong, Y., 2011. Fish stem cell cultures. Int. J. Biol. Sci. 7, 392-402.

Horvath, A., Wayman, W.R., Urbanyi, B., Ware, K.M., Dean, J.C., Tiersch, T.R., 2005. The relationship of the cryoprotectants methanol and dimethyl sulfoxide and hyperosmotic extenders on sperm cryopreservation of two North-American sturgeon species. Aquaculture. 247, 243-251.

Horváth, Á., 2007. Cryobank of common carp sperm, a tool for the preservation of genetic resources, Workshop on Characterization and Conservation of Common 
Carp Genetic Resources, Research Institute for Fisheries, Aquaculture and Irrigation, Szarvas, Hungary.

Horváth, Á., Bokor, Z., Bernáth, G., Csenki, Z., Gorjan, A., Herráez, M.P., Urbányi, B., Jesenšek, D., 2015. Very low sperm-egg ratios result in successful fertilization using cryopreserved sperm in the Adriatic grayling (Thymallus thymallus). Aquaculture. 435, 75-77.

Horváth, Á., Jesenšek, D., Csorbai, B., Bokor, Z., Raboczki, É., Kaczkó, D., Bernáth, G., Hoitsy, G., Urbányi, B., Bajec, S.S., Snoj, A., 2012. Application of sperm cryopreservation to hatchery practice and species conservation: A case of the Adriatic grayling (Thymallus thymallus). Aquaculture. 358-359, 213-215.

Horváth, L., Orbán, L., 1995. Genome and gene manipulation in the common carp. Aquaculture. 129, 157-181.

Hu, E., Tiersch, T.R., 2011. Development of high-throughput cryopreservation for aquatic species. In: Tiersch, T.R., Green, C.C. (Eds.), Cryopreservation in Aquatic Species, 2nd Ed. World Aquaculture Society, Baton Rouge, Louisiana, pp. $995-1003$.

Hu, E., Liao, T.W., Tiersch, T.R., 2013. A quality assurance initiative for commercialscale production in high-throughput cryopreservation of blue catfish sperm. Cryobiology. 67, 214-224.

Ieropoli, S., Masullo, P., Santo, M.D.E., Sansone, G., 2004. Effects of extender composition, cooling rate and freezing on the fertilisation viability of spermatozoa of the Pacific oyster (Crassostrea gigas). Cryobiology. 49, 250257. 
Imamura, M., Aoi, T., Tokumasu, A., Mise, N., Abe, K., Yamanaka, S., Noce, T., 2010. Induction of primordial germ cells from mouse induced pluripotent stem cells derived from adult hepatocytes. Mol. Reprod. Dev. 77, 802-811.

Isayeva, A., Zhang, T., Rawson, D.M., 2004. Studies on chilling sensitivity of zebrafish (Danio rerio) oocytes. Cryobiology. 49, 114-122.

Ishii, T., 2014. Human iPS cell-derived germ cells: current status and clinical potential. J. Clin. Med. 3, 1064-1083.

Janik, M., Kleinhans, F.W., Hagedorn, M., 2000. Overcoming a permeability barrier by microinjecting cryoprotectants into zebrafish embryos (Brachydanio rerio). Cryobiology. 41, 25-34.

Judycka, S., Szczepkowski, M., Ciereszko, A., Dietrich, G.J., 2015. New extender for cryopreservation of Siberian sturgeon (Acipenser baerii) semen. Cryobiology. $70,184-189$.

Kane, D.A., Kimmel, C.B., 1993. The zebrafish midblastula transition. Development (Cambridge, England). 119, 447-456.

Kawamoto, T., Narita, T., Isowa, K., Aoki, H., Hayashi, M., Komaru, A., Ohta, H., 2007. Effects of cryopreservation methods on post-thaw motility of spermatozoa from the Japanese pearl oyster, Pinctada fucata martensii. Cryobiology. 54, 1926.

Kiriyakit, A., Gallardo, W.G., Bart, A.N., 2011. Successful hybridization of groupers (Epinephelus coioides x Epinephelus lanceolatus) using cryopreserved sperm. Aquaculture. 320, 106-112.

Komen, H., Thorgaard, G.H., 2007. Androgenesis, gynogenesis and the production of clones in fishes: A review. Aquaculture. 269, 150-173. 
Kopeika, E., Kopeika, J., Zhang, T., 2007. Cryopreservation of fish sperm. Method. Mol. Biol. (Clifton, N.J.). 368, 203-217.

Krone, A., Wittbrodt, J., 1997. A simple and reliable protocol for cryopreservation of medaka Oryzias latipes spermatozoa. Fish Biol. J. Medaka. 9, 47-48.

Kurokura, H., Hirano, R., 1980. Cryopreservation of rainbow trout sperm. Bull. Japanese Soc. Sci. Fish. 46, 1493-1495.

Kusuda, S., Koide, N., Kawamula, H., Teranishi, T., Nakajima, J.-i., Yamaha, E., Arai, K., Ohta, H., 2005. Cryopreservation diluents for spermatozoa of Sakhalin taimen Hucho perryi. Fisheries Sci. 71, 293-298.

Kutluyer, F., Kayim, M., Öğretmen, F., Büyükleblebici, S., Tuncer, P.B., 2014. Cryopreservation of rainbow trout Oncorhynchus mykiss spermatozoa: Effects of extender supplemented with different antioxidants on sperm motility, velocity and fertility. Cryobiology. 69, 462-466.

Labbe, C., Depince, A., Le Bail, P.-Y., Williot, P., 2011. One alternative to germ cells cryopreservation: cryobanking of somatic cells in sturgeon. In: Williot, P., Rochard, E., Desse-Berset, N., Kirschbaum, F., Gessner, J. (Eds.), Biology and Conservation of the European Sturgeon Acipenser sturio L. 1758. Springer Berlin Heidelberg, pp. 621-633.

Labbé, C., Robles, V., Herraez, M.P., 2013. Cryopreservation of gametes for aquaculture and alternative cell sources for genome preservation. In: Allan, G., Burnell, G. (Eds.), Advances in Aquaculture Hatchery Technology. Woodhead Publishing, pp. 76-116.

Lahnsteiner, F., 2008. The effect of internal and external cryoprotectants on zebrafish (Danio rerio) embryos. Theriogenology. 69, 384-396. 
Lahnsteiner, F., Mansour, N., Kunz, F.A., 2011. The effect of antioxidants on the quality of cryopreserved semen in two salmonid fish, the brook trout (Salvelinus fontinalis) and the rainbow trout (Oncorhynchus mykiss). Theriogenology. 76, $882-890$

Lahnsteiner, F., Berger, B., Weismann, T., Patzner, R., 1996. The influence of various cryoprotectants on semen quality of the rainbow trout (Oncorhynchus mykiss) before and after cryopreservation. J. Appl. Ichthyol. 12, 99-106.

Lakra, W.S., Swaminathan, T.R., Joy, K.P., 2011. Development, characterization, conservation and storage of fish cell lines: a review. Fish Physiol. Biochem. 37, $1-20$.

Lezcano, M., Granja, C., Salazar, M., 2004. The use of flow cytometry in the evaluation of cell viability of cryopreserved sperm of the marine shrimp (Litopenaeus vannamei). Cryobiology. 48, 349-356.

Li, P., Hulak, M., Li, Z.H., Sulc, M., Psenicka, M., Rodina, M., Gela, D., Linhart, O., 2013. Cryopreservation of common carp (Cyprinus carpio L.) sperm induces protein phosphorylation in tyrosine and threonine residues. Theriogenology. 80, 84-89.

Li, P., Hulak, M., Koubek, P., Sulc, M., Dzyuba, B., Boryshpolets, S., Rodina, M., Gela, D., Manaskova-Postlerova, P., Peknicova, J., Linhart, O., 2010. Ice-age endurance: the effects of cryopreservation on proteins of sperm of common carp, Cyprinus carpio L. Theriogenology. 74, 413-423.

Lim, H.K., Le, M.H., 2013. Evaluation of extenders and cryoprotectants on motility and morphology of longtooth grouper (Epinephelus bruneus) sperm. Theriogenology. 79, 867-871. 
Lind, C.E., Ponzoni, R.W., Nguyen, N.H., Khaw, H.L., 2012. Selective breeding in fish and conservation of genetic resources for aquaculture. Reprod. Domest. Anim. $47,255-263$.

Linhart, O., Rodina, M., Cosson, J., 2000. Cryopreservation of sperm in common carp Cyprinus carpio: sperm motility and hatching success of embryos. Cryobiology. 41, 241-250.

Linhart, O., Rodina, M., Flajshans, M., Gela, D., Kocour, M., 2005. Cryopreservation of European catfish Silurus glanis sperm: Sperm motility, viability, and hatching success of embryos. Cryobiology. 51, 250-261.

Liu, Q.H., Ma, D.Y., Xu, S.H., Xiao, Z.Z., Xiao, Y.S., Song, Z.C., Li, J., 2015. Summer flounder (Paralichthys dentatus) sperm cryopreservation and application in interspecific hybridization with olive flounder (P olivaceus). Theriogenology. 83, 703-710.

Liu, X.H., Zhang, T., Rawson, D.M., 2001a. Differential scanning calorimetry studies of intraembryonic freezing and cryoprotectant penetration in zebrafish (Danio rerio) embryos. J. Exp. Zool. 290, 299-310.

Liu, X.H., Zhang, T., Rawson, D.M., 2001b. Effect of cooling rate and partial removal of yolk on the chilling injury in zebrafish (Danio rerio) embryos. Theriogenology. 55, 1719-1731.

Liu, Y., Li, X., 2015. Successful oocyte cryopreservation in the blue mussel Mytilus galloprovincialis. Aquaculture. 438, 55-58.

Liu, Y., Xu, T., Robinson, N., Qin, J., Li, X., 2014. Cryopreservation of sperm in farmed Australian greenlip abalone Haliotis laevigata. Cryobiology. 68, 185193. 
Lubzens, E., Daube, N., Pekarsky, I., Magnus, Y., Cohen, A., Yusefovich, F., Feigin, P., 1997. Carp (Cyprinus carpio L.) spermatozoa cryobanks — strategies in research and application. Aquaculture. 155, 13-30.

Luo, C., Lu, F., Wang, X., Wang, Z., Li, X., Gong, F., Jiang, J., Liu, Q., Shi, D., 2013. Treatment of donor cells with trichostatin A improves in vitro development and reprogramming of buffalo (Bubalus bubalis) nucleus transfer embryos. Theriogenology. 80, 878-886.

Luo, D., Hu, W., Chen, S., Xiao, Y., Sun, Y., Zhu, Z., 2009. Identification of differentially expressed genes between cloned and zygote-developing zebrafish (Danio rerio) embryos at the dome stage using suppression subtractive hybridization. Biol. Reprod. 80, 674-684.

Ma, C., Fan, L., Ganassin, R., Bols, N., Collodi, P., 2001. Production of zebrafish germline chimeras from embryo cell cultures. P. Natl. Acad. Sci. USA. 98, 24612466.

Magyary, I., Urbányi, B., Horváth, L., 1996. Cryopreservation of common carp (Cyprinus carpio L.) sperm I. The importance of oxygen supply. J. Appl. Ichthyol. 12, 113-115.

Maria, A.N., Viveiros, A.T.M., Freitas, R.T.F., Oliveira, A.V., 2006. Extenders and cryoprotectants for cooling and freezing of piracanjuba (Brycon orbignyanus) semen, an endangered Brazilian teleost fish. Aquaculture. 260, 298-306.

Maria, A.N., Carvalho, A.C.M., Araújo, R.V., Santos, J.P., Carneiro, P.C.F., Azevedo, H.C., 2015. Use of cryotubes for the cryopreservation of tambaqui fish semen (Colossoma macropomum). Cryobiology. 70, 109-114. 
Martínez-Páramo, S., Pérez-Cerezales, S., Robles, V., Anel, L., Herráez, M.P., 2008. Incorporation of antifreeze proteins into zebrafish embryos by a non-invasive method. Cryobiology. 56, 216-222.

Martínez-Páramo, S., Barbosa, V., Pérez-Cerezales, S., Robles, V., Herráez, M.P., 2009a. Cryoprotective effects of antifreeze proteins delivered into zebrafish embryos. Cryobiology. 58, 128-133.

Martínez-Páramo, S., Pérez-Cerezales, S., Gómez-Romano, F., Blanco, G., Sánchez, J.A., Herráez, M.P., 2009b. Cryobanking as tool for conservation of biodiversity: effect of brown trout sperm cryopreservation on the male genetic potential. Theriogenology. 71, 594-604.

Martínez-Páramo, S., Diogo, P., Dinis, M.T., Herráez, M.P., Sarasquete, C., Cabrita, E., 2012. Incorporation of ascorbic acid and $\alpha$-tocopherol to the extender media to enhance antioxidant system of cryopreserved seabass sperm. Theriogenology. $77,1129-1136$.

Martínez-Páramo, S., Diogo, P., Dinis, M.T., Soares, F., Sarasquete, C., Cabrita, E., 2013. Effect of two sulfur-containing amino acids, taurine and hypotaurine in European sea bass (Dicentrarchus labrax) sperm cryopreservation. Cryobiology. 66, 333-338.

McDonald, T.M., Pascual, A.S., Uppalapati, C.K., Cooper, K.E., Leyva, K.J., Hull, E.E., 2013. Zebrafish keratocyte explant cultures as a wound healing model system: Differential gene expression \& morphological changes support epithelial-mesenchymal transition. Exp. Cell Res. 319, 1815-1827.

Morais, S., Aragao, C., Cabrita, E., Estevez, A., Yúfera, M., Valente, L.M.P., Conceiçao, L.E.C., Dias, J., Engrola, S., Gisbert, E., Costas B., Constenla, M., Mañanós, E., Duncan, N., Dinis, M.T. 2014. New developments and biological 
insights into the farming of Solea senegalensis reinforcing its aquaculture potential. Reviews in Aquaculture 6, 1-37.

Moritz, C., Labbe, C., 2008. Cryopreservation of goldfish fins and optimization for field scale cryobanking. Cryobiology. 56, 181-188.

Morris, G.J., 2005. The origin, ultrastructure, and microbiology of the sediment accumulating in liquid nitrogen storage vessels. Cryobiology. 50, 231-238.

Müller, T., Horváth, Á., Takahashi, E., Kolics, B., Bakos, K., Decsi, K., Kovács, B., Taller, J., Urbányi, B., Bercsényi, M., Horváth, L., Adachi, S., Arai, K., Yamaha, E., 2012. Artificial hybridization of Japanese and European eel (Anguilla japonica $\mathrm{x}$ A. anguilla) by using cryopreserved sperm from freshwater reared males. Aquaculture. 350-353, 130-133.

National Research Council. 1993. Managing Global Genetic Resources: Livestock. National Academy Press, Washington, D.C.

Neves, P.R., Ribeiro, R.P., Streit, D.P.J., Natali, M.R.M., Fornari, D.C., Santos, A.I., Godoy, L.C., 2014. Injuries in pacu embryos (Piaractus mesopotamicus) after freezing and thawing. Zygote. 22, 25-31.

Nynca, J., Arnold, G.J., Fröhlich, T., Ciereszko, A., 2015a. Cryopreservation-induced alterations in protein composition of rainbow trout semen. PROTEOMICS. doi:10.1002/pmic.201400525.

Nynca, J., Dietrich, G.J., Dobosz, S., Grudniewska, J., Ciereszko, A., 2014. Effect of cryopreservation on sperm motility parameters and fertilizing ability of brown trout semen. Aquaculture. 433, 62-65.

Nynca, J., Dietrich, G.J., Dobosz, S., Zalewski, T., Ciereszko, A., 2015b. Effect of postthaw storage time and sperm-to-egg ratio on fertility of cryopreserved brook trout sperm. Theriogenology. 83, 253-256. 
Nynca, J., Dietrich, G.J., Grudniewska, J., Dobosz, S., Liszewska, E., Krzyś, M., Różyński, R., Ciereszko, A., 2015c. Efficient method for cryopreservation of European huchen (Hucho hucho L.) and grayling (Thymallus thymallus L.) semen. Aquaculture. 435, 146-151.

O'Reilly, P., Doyle, R., 2007. Live gene banking of endangered populations of Atlantic salmon, The Atlantic Salmon. Blackwell Publishing Ltd, pp. 425-469.

O'Brien, J.K., Robeck, T.R., 2010. The value of ex situ cetacean populations in understanding reproductive physiology and developing assisted reproductive technology for ex situ and in situ species management and conservation efforts. Int. J. Comp. Psychol. 23, 227-248.

Öğretmen, F., İnanan, B.E., 2014a. Evaluation of cryoprotective effect of Turkish pine honey on common carp (Cyprinus carpio) spermatozoa. Cryoletters. 35, 427437.

Öğretmen, F., İnanan, B.E., 2014b. Effect of butylated hydroxytoluene (BHT) on the cryopreservation of common carp (Cyprinus carpio) spermatozoa. Anim. Reprod. Sci. 151, 269-274.

Öğretmen, F., İnanan, B.E., Öztürk, M., 2014. Protective effects of propolis on cryopreservation of common carp (Cyprinus carpio) sperm. Cryobiology. 68, 107-112.

Öğretmen, F., İnanan, B.E., Kutluyer, F., Kayim, M., 2015. Effect of semen extender supplementation with cysteine on postthaw sperm quality, DNA damage, and fertilizing ability in the common carp (Cyprinus carpio). Theriogenology. 83, $1548-1552$.

Orfão, L.H., Nascimento, A.F., Corrêa, F.M., Cosson, J., Viveiros, A.T.M., 2011. Extender composition, osmolality and cryoprotectant effects on the motility of 
sperm in the Brazilian endangered species Brycon opalinus (Characiformes). Aquaculture. 311, 241-247.

Osipova, V.P., Kolyada, M.N., Berberova, N.T., Milaeva, E.R., Ponomareva, E.N., Belaya, M.M., 2014. Cryoprotective effect of phosphorous-containing phenolic anti-oxidant for the cryopreservation of beluga sperm. Cryobiology. 69, 467472.

Paniagua-Chavez, C.G., Tiersch, T.R., 2001. Laboratory studies of cryopreservation of sperm and trochophore larvae of the Eastern oyster. Cryobiology. 43, 211-223. Paniagua-Chavez, C.G., Buchanan, J.T., Supan, J.E., Tiersch, T., 2000.

Cryopreservation of sperm and larvae of the Eastern oyster. In: Tiersch, T.R., Mazik, P.M. (Eds.), Cryopreservation in aquatic species. WAS, pp. 230-239. Paniagua-Chávez, C.G., Jenkins, J., Segovia, M., Tiersch, T.R., 2006. Assessment of gamete quality for the eastern oyster (Crassostrea virginica) by use of fluorescent dyes. Cryobiology. 53, 128-138.

Paredes, E., Bellas, J., Adams, S.L., 2013. Comparative cryopreservation study of trochophore larvae from two species of bivalves: Pacific oyster (Crassostrea gigas) and Blue mussel (Mytilus galloprovincialis). Cryobiology. 67, 274-279.

Paredes, E., Adams, S.L., Tervit, H.R., Smith, J.F., McGowan, L.T., Gale, S.L., Morrish, J.R., Watts, E., 2012. Cryopreservation of Greenshell mussel (Perna canaliculus) trochophore larvae. Cryobiology. 65, 256-262.

Pei, D.S., Sun, Y.H., Chen, S.P., Wang, Y.P., Hu, W., Zhu, Z.Y., 2007. Identification of differentially expressed genes from the cross-subfamily cloned embryos derived from zebrafish nuclei and rare minnow enucleated eggs. Theriogenology. 68, 1282-1291. 
Peñaranda, D.S., Pérez, L., Gallego, V., Jover, M., Asturiano, J.F., 2009. Improvement of European eel sperm cryopreservation method by preventing spermatozoa movement activation caused by cryoprotectants. Cryobiology. 59, 119-126.

Pérez-Cerezales, S., Gutiérrez-Adán, A., Martínez-Páramo, S., Beirão, J., Herráez, M.P., 2011. Altered gene transcription and telomere length in trout embryo and larvae obtained with DNA cryodamaged sperm. Theriogenology. 76, 1234-1245.

Pessoa, N.O., Galvão, J.A.S., de Souza Filho, F.G.M., de Sousa, M.L.N.M., Sampaio, C.M.S., 2014. Cooling of pirapitinga (Piaractus brachypomus) embryos stored at $-10^{\circ} \mathrm{C}$. Zygote. FirstView, 1-7.

Pineault, N., Abu-Khader, A., 2015. Advances in umbilical cord blood stem cell expansion and clinical translation. Exp. Hematol. 43, 498-513.

Plachinta, M., Zhang, T., Rawson, D.M., 2004. Studies on cryoprotectant toxicity to zebrafish (Danio rerio) oocytes. Cryoletters. 25, 415-424.

Poikane, S., Zampoukas, N., Borja, A., Davies, S.P., van de Bund, W., Birk, S., 2014. Intercalibration of aquatic ecological assessment methods in the European Union: Lessons learned and way forward. Environ. Sci. Policy. 44, 237-246.

Poss, K.D., Keating, M.T., Nechiporuk, A., 2003. Tales of regeneration in zebrafish. Dev. Dynam. 226, 202-210.

Rahman, S.M., Strüssmann, C.A., Majhi, S.K., Suzuki, T., Watanabe, M., 2011. Efficiency of osmotic and chemical treatments to improve the permeation of the cryoprotectant dimethyl sulfoxide to Japanese whiting (Sillago japonica) embryos. Theriogenology. 75, 248-255.

Rall, W., Grieder, F., Chang, M., 2011. Cryopreservation of germplasm for effective management of animal genetic resources. In: Tiersch, T.R., Green, C.C. (Eds.), 
Cryopreservation in Aquatic Species, 2nd Ed. World Aquaculture Society, Baton Rouge, Louisiana, pp. 794-795.

Rasines, I., Gómez, M., Martín, I., Rodríguez, C., Mañanós, E., Chereguini, O., 2013. Artificial fertilisation of cultured Senegalese sole (Solea senegalensis): Effects of the time of day of hormonal treatment on inducing ovulation. Aquaculture. 392-395, 94-97.

Renard, P., 1991. Cooling and freezing tolarances in embryos of the Pacific oyster, Crassostrea gigas: methanol and sucrose effects. Aquaculture. 92, 43-57.

Resende, E.K., Marques, D.K.S., 2009. Criopreservação de sêmen de peixe. Embrapa Pantanal. Circular Técnica 84. Available at http://www.cpap.embrapa.br/publicacoes/online/CT84.pdf.

Rhodes, L., Smith, J., Tervit, R., Roberts, R., Adamson, J., Adams, S., Decker, M., 2006. Cryopreservation of economically valuable marine micro-algae in the classes Bacillariophyceae, Chlorophyceae, Cyanophyceae, Dinophyceae, Haptophyceae, Prasinophyceae, and Rhodophyceae. Cryobiology. 52, 152-156.

Riesco, M.F., Valcarce, D.G., Alfonso, J., Herraez, M.P., Robles, V., 2014. In vitro generation of zebrafish PGC-like cells. Biol. Reprod. 91, 114.

Riesco, M.F., Félix, F., Matias, D., Joaquim, S., Suquet, M., Cabrita, E. First study in cryopreserved sperm of Crassostrea angulata. General and Comparative Endocrinology (in press).

Robeck, T.R., Steinman, K.J., Gearhart, S., Reidarson, T.R., McBain, J.F., Monfort, S.L., 2004. Reproductive physiology and development of artificial insemination technology in killer whales (Orcinus orca). Biol. Reprod. 71, 650-660.

Robeck, T.R., Gearhart, S.A., Steinman, K.J., Katsumata, E., Loureiro, J.D., O'Brien, J.K., 2011. In vitro sperm characterization and development of a sperm 
cryopreservation method using directional solidification in the killer whale (Orcinus orca). Theriogenology. 76, 267-279.

Robeck, T.R., Montano, G.A., Steinman, K.J., Smolensky, P., Sweeney, J., Osborn, S., O’Brien, J.K., 2013. Development and evaluation of deep intra-uterine artificial insemination using cryopreserved sexed spermatozoa in bottlenose dolphins (Tursiops truncatus). Anim. Reprod. Sci. 139, 168-181.

Robles, V., Marti, M., Izpisua Belmonte, J.C., 2011. Study of pluripotency markers in zebrafish embryos and transient embryonic stem cell cultures. Zebrafish. 8, 5763.

Robles, V., Cabrita, E., Cunado, S., Herraez, M.P., 2003a. Sperm cryopreservation of sex-reversed rainbow trout (Oncorhynchus mykiss): parameters that affect its ability for freezing. Aquaculture. 224, 203-212.

Robles, V., Cabrita, E., Acker, J.P., Herraez, M.P., 2008. Embryo cryopreservation: what we know until now? In: Cabrita, E., Robles, V., Herraez, M.P. (Eds.), Methods in reproductive aquaculture. C.R.C. Press, Boca Raton, pp. 261- 294.

Robles, V., Cabrita, E., Real, M., Alvarez, R., Herraez, M.P., 2003b. Vitrification of turbot embryos: preliminary assays. Cryobiology. 47, 30-39.

Robles, V., Barbosa, V., Herraez, M.P., Martinez-Paramo, S., Cancela, M.L., 2007. The antifreeze protein type I (AFP I) increases seabream (Sparus aurata) embryos tolerance to low temperatures. Theriogenology. 68, 284-289.

Robles, V., Cabrita, E., de Paz, P., Cunado, S., Anel, L., Herraez, M.P., 2004. Effect of a vitrification protocol on the lactate dehydrogenase and glucose-6-phosphate dehydrogenase activities and the hatching rates of Zebrafish (Danio rerio) and Turbot (Scophthalmus maximus) embryos. Theriogenology. 61, 1367-1379. 
Robles, V., Cabrita, E., Fletcher, G.L., Shears, M.A., King, M.J., Herraez, M.P., 2005. Vitrification assays with embryos from a cold tolerant sub-arctic fish species. Theriogenology. 64, 1633-1646.

Robles, V., Martínez-Pastor, F., Petroni, G., Riesco, M.F., Bozzano, A., Villanueva, R., 2013. Cryobiology of cephalopod (Illex coindetii) spermatophores. Cryobiology. 66, 288-294.

Robles, V., Riesco, M.F., Psenicka, M., Saito, T., Valcarce, D,G., Cabrita, E., Herráez, M.P. In press. Biology of teleost primordial germ cells (PGCs) and spermatogonia: biotechnological applications. Aquaculture, (in press).

Rodina, M., Gela, D., Kocour, M., Alavi, S.M.H., Hulak, M., Linhart, O., 2007. Cryopreservation of tench, Tinca tinca, sperm: Sperm motility and hatching success of embryos. Theriogenology. 67, 931-940.

Rodriguez-Wallberg, K.A., 2015. Clinical aspects and perinatal outcomes after cryopreservation of embryos and gametes. Minerva ginecol. 67, 207-215.

Rurangwa, E., Volckaert, F.A.M., Huyskens, G., Kime, D.E., Ollevier, F., 2001. Quality control of refrigerated and cryopreserved semen using computer-assisted sperm analysis (CASA), viable staining and standardized fertilization in African catfish (Clarias gariepinus). Theriogenology. 55, 751-769.

Sanches, E.G., Oliveira, I.R., Serralheiro, P.C.d.S., Cerqueira, V.R., 2013.

Cryopreservation of mutton snapper (Lutjanus analis) sperm. Anais da Academia Brasileira de Ciências. 85, 1083-1092.

Sarvi, K., Niksirat, H., Mojazi Amiri, B., Mirtorabi, S.M., Rafiee, G.R., Bakhtiyari, M., 2006. Cryopreservation of semen from the endangered Caspian brown trout (Salmo trutta caspius). Aquaculture. 256, 564-569. 
Scheerer, P.D., Thorgaard, G.H., Allendorf, F.W., 1991. Genetic analysis of androgenetic rainbow trout. J. Exp. Zool. 260, 382-390.

Seki, S., Kouya, T., Tsuchiya, R., Valdez Jr, D.M., Jin, B., Koshimoto, C., Kasai, M., Edashige, K., 2011. Cryobiological properties of immature zebrafish oocytes assessed by their ability to be fertilized and develop into hatching embryos. Cryobiology. 62, 8-14.

Seki, S., Kouya, T., Tsuchiya, R., Valdez, D.M., Jin, B., Hara, T., Saida, N., Kasai, M., Edashige, K., 2008. Development of a reliable in vitro maturation system for zebrafish oocytes. Reproduction. 135, 285-292.

Siripattarapravat, K., Pinmee, B., Venta, P.J., Chang, C.-C., Cibelli, J.B., 2009. Somatic cell nuclear transfer in zebrafish. Nat. Meth. 6, 733-735.

Siripattarapravat, K., Pinmee, B., Chang, E.A.H., Muñoz, J.D., Kawakami, K., Cibelli, J.B., 2011. The influence of donor nucleus source on the outcome of zebrafish somatic cell nuclear transfer. Int. J. Dev. Biol. 54, 1679-1683.

Smith, J.F., Adams, S.L., Gale, S.L., McGowan, L.T., Tervit, H.R., Roberts, R.D., 2012. Cryopreservation of Greenshell ${ }^{\mathrm{TM}}$ mussel (Perna canaliculus) sperm. I. Establishment of freezing protocol. Aquaculture. 334-337, 199-204.

Sorrenti, G., Bagnoli, A., Miraglia, V., Crocetta, F., Vitiello, V., Ristoratore, F., Cirino, P., Sansone, G., Sordino, P., 2014. Investigating sperm cryopreservation in a model tunicate, Ciona intestinalis sp. A. Cryobiology. 68, 43-49.

Spiegler, M.A., Oppenheimer, S.B., 1995. Extending the viability of sea urchin gametes. Cryobiology. 32, 168-174.

Streit Jr., D.P., Godoy, L.C., Ribeiro, R.P., Fornari, D.C., Digmayer, M., Zhang, T., 2014. Cryopreservation of embryos and oocytes of south american fish species. In: Yamashiro, H. (Ed.), Recent Advances in Cryopreservation. Intech. 
Streit Jr., D.P., Fornari, D.C., Povh, J.A., de Godoy, L.C., Lopes de Oliveira, C.A., Kawakami de Resende, E., Ribeira Pereiro, R., 2013. Germplasm banking and its role on development of the genetic improvement program for fish in Brazil. In: Martínez-Páramo, S., Oliveira, C., Dinis, M.T. (Eds.), $4^{\text {th }}$ International Workshop on the Biology of Fish Gametes, Centre of Marine Sciences (CCMAR), University of Algarve, Faro, Portugal, Albufeira, Portugal, pp. 140141.

Sun, L., Bradford, C.S., Ghosh, C., Collodi, P., Barnes, D.W., 1995. ES-like cell cultures derived from early zebrafish embryos. Mol. Mar. Biol. Biotechnol. 4, 193-199.

Sun, Y.-H., Chen, S.-P., Wang, Y.-P., Hu, W., Zhu, Z.-Y., 2005. Cytoplasmic impact on cross-genus cloned fish derived from transgenic common carp (Cyprinus carpio) nuclei and goldfish (Carassius auratus) enucleated eggs. Biol. Reprod. 72, 510515.

Suquet, M., Le Mercier, A., Rimond, F., Mingant, C., Haffray, P., Labbe, C., 2012. Setting tools for the early assessment of the quality of thawed Pacific oyster (Crassostrea gigas) D-larvae. Theriogenology. 78, 462-467.

Suquet, M., Labbé, C., Puyo, S., Mingant, C., Quittet, B., Boulais, M., Queau, I., Ratiskol, D., Diss, B., Haffray, P., 2014. Survival, growth and reproduction of cryopreserved larvae from a marine Invertebrate, the Pacific oyster (Crassostrea gigas). PLoS ONE. 9, e93486.

Symonds, J.E., Bowman, S., 2007. Atlantic cod genomics and broodstock development in Canada. Aquaculture. 272, Supplement 1, S313.

Takahashi, K., Yamanaka, S., 2006. Induction of pluripotent stem cells from mouse embryonic and adult fibroblast cultures by defined factors. Cell. 126, 663-676. 
Tan, E., Yang, H., Tiersch, T.R., 2010. Determination of sperm concentration for smallbodied biomedical model fishes by use of microspectrophotometry. Zebrafish. 7, 233-240.

Tanaka, S., Zhang, H., Horie, N., Yamada, Y., Okamura, A., Utoh, T., Mikawa, N., Oka, H.P., Kurokura, H., 2002. Long-term cryopreservation of sperm of Japanese eel. J. Fish Biol. 60, 139-146.

Tervit, H.R., Adams, S.L., Roberts, R.D., McGowan, L.T., Pugh, P.A., Smith, J.F., Janke, A.R., 2005. Successful cryopreservation of Pacific oyster (Crassostrea gigas) oocytes. Cryobiology. 51, 142-151.

Thurston, L.M., Watson, P.F., 2002. Semen cryopreservation: a genetic explanation for species and individual variation? CryoLetters. 23, 255-262.

Tiersch, T.R., 2001. Cryopreservation in aquarium fishes. Mar. Biotechnol. 3, S212S223.

Tiersch, T.R., 2011. Process pathways for sperm cryopreservation research, application, and commercialization. In: Tiersch, T.R., Green, C. (Eds.), Cryopreservation in Aquatic Species, 2nd Ed. World Aquaculture Society, Baton Rouge, Louisiana, pp. 646-671.

Tiersch, T.R., Yang, H., Hu, E., 2011. Outlook for development of high-throughput cryopreservation for small-bodied biomedical model fishes. Comp. Biochem. Phys. C. $154,76-81$.

Tiersch, T.R., Yang, H., Jenkins, J.A., Dong, Q., 2007. Sperm cryopreservation in fish and shellfish. Soc. Reprod. Fertil. Suppl. 65, 493-508.

Tiersch, T.R., Figiel, C.R., Wayman, W.R., Williamson, J.H., Carmichael, G.J., Gorman, O.T., 1998. Cryopreservation of sperm of the endangered razorback sucker. T. Am. Fish. Soc. 127, 95-104. 
Tiersch, T.R., Figiel Jr, C.R., Wayman, W.R., Williamson, J.H., Gorman, O.T., Carmichael, G.J., 2004. Cryopreservation of sperm from the endangered colorado pikeminnow. N. Am. J. Aquacult. 66, 8-14.

Tsai, S., Rawson, D.M., Zhang, T., 2009a. Studies on chilling sensitivity of early stage zebrafish (Danio rerio) ovarian follicles. Cryobiology. 58, 279-286.

Tsai, S., Rawson, D.M., Zhang, T., 2009b. Development of cryopreservation protocols for early stage zebrafish (Danio rerio) ovarian follicles using controlled slow cooling. Theriogenology. 71, 1226-1233.

Tsai, S., Rawson, D.M., Zhang, T., 2010. Development of in vitro culture method for early stage zebrafish (Danio rerio) ovarian follicles for use in cryopreservation studies. Theriogenology. 74, 290-303.

Tsai, S., Kuit, V., Lin, Z.G., Lin, C., 2014. Application of a functional marker for the effect of cryoprotectant agents on Gorgonian coral (Junceella juncea and J. fragilis) sperm sacs. Cryoletters. 35, 1-7.

Usuki, H., Hamaguchi, M., Ishioka, H., 2002. Effects of developmental stage, seawater concentration and rearing temperature on cryopreservation of Pacific oyster Crassostrea gigas larvae. Fisheries Sci. 68, 757-762.

Valdez, J., Delgado M., Miyamoto, A., Hara, T., Edashige, K., Kasai, M., 2005. Sensitivity to chilling of medaka (Oryzias latipes) embryos at various developmental stages. Theriogenology. 64, 112-122.

Van Der Walt, L.D., Van Der Bank, F.H., Steyn, G.J., 1993. The suitability of using cryopreservation of spermatozoa for the conservation of genetic diversity in African catfish (Clarias gariepinus). Comp. Biochem. Phys. A. 106, 313-318. 
Varela Junior, A.S., Goularte, K.L., Alves, J.P., Pereira, F.A., Silva, E.F., Cardoso, T.F., Jardim, R.D., Streit Jr, D.P., Corcini, C.D., 2015. Methods of cryopreservation of Tambaqui semen, Colossoma macropomum. Anim. Reprod. Sci. 157, 71-77.

Varga, Z., Westerfield, M., 2011. Sperm cryopreservation and storage at the Zebrafish International Resource Center. In: Tiersch, T.R., Green, C.C. (Eds.), Cryopreservation in Aquatic Species, 2nd Ed. World Aquaculture Society, Baton Rouge, Louisiana, pp. 809-819.

Vitiello, V., Carlino, P.A., Del Prete, F., Langellotti, A.L., Sansone, G., 2011. Effects of cooling and freezing on the motility of Ostrea edulis (L., 1758) spermatozoa after thawing. Cryobiology. 63, 118-124.

Viveiros, A.T., Godinho, H.P., 2009. Sperm quality and cryopreservation of Brazilian freshwater fish species: a review. Fish Physiol. Biochem. 35, 137-150.

Viveiros, A.T.M., 2005. Semen cryopreservation in catfish species, with particular emphasis on the African catfish. Anim. Breed. Abs. 73, 1N-9N.

Viveiros, A.T.M., Orfão, L.H., Leal, M.C., 2014. Biologia e conservação de espermatozoides. In: Baldisserotto, B., Cyrino, J.E.P., Urbinati, E.C. (Eds.), Biologia e Fisiologia de Peixes Neotropicais de Água Doce. FUNEP, UNESP, Jaboticabal, pp. 307-327.

Viveiros, A.T.M., Isaú, Z.A., Caneppele, D., Leal, M.C., 2012. Sperm cryopreservation affects postthaw motility, but not embryogenesis or larval growth in the Brazilian fish Brycon insignis (Characiformes). Theriogenology. 78, 803-810.

Vuthiphandchai, V., Chomphuthawach, S., Nimrat, S., 2009. Cryopreservation of red snapper (Lutjanus argentimaculatus) sperm: Effect of cryoprotectants and cooling rates on sperm motility, sperm viability, and fertilization capacity. Theriogenology. 72, 129-138. 
Vuthiphandchai, V., Nimrat, S., Kotcharat, S., Bart, A.N., 2007. Development of a cryopreservation protocol for long-term storage of black tiger shrimp (Penaeus monodon) spermatophores. Theriogenology. 68, 1192-1199.

Wakamatsu, Y., Ozato, K., Sasado, T., 1994. Establishment of a pluripotent cell line derived from a medaka (Oryzias latipes) blastula embryo. Mol. Mar. Biol. Biotechnol. 3, 185-191.

Walter, R., 2011. Xiphophorus fishes: varieties and genetic resources. In: Tiersch, T.R., Green, C.C. (Eds.), Cryopreservation in Aquatic Species, 2nd Ed. World Aquaculture Society, Baton Rouge, Louisiana, pp. 796- 808.

Walters, E.M., Benson, J.D., Woods, E.J., Critser, J.K., 2009. The history of sperm cryopreservation. In: Pacey, A.A., Tomlinson, M.J. (Eds.), Sperm banking, theory and practice. Cambridge University Press, Cambridge, pp. 1-17.

Wang, H., Li, X., Wang, M., Clarke, S., Gluis, M., Zhang, Z., 2011. Effects of larval cryopreservation on subsequent development of the blue mussels, Mytilus galloprovincialis Lamarck. Aquac. Res. 42, 1816-1823.

Wang, R., Guan, M., Rawson, D., Zhang, T., 2008. Ultrasound enhanced methanol penetration of zebrafish (Danio rerio) embryos measured by permittivity changes using impedance spectroscopy. Eur. Biophys. J. 37, 1039-1044.

Wayman, W., 2011. Germplasm repository programs in the United States Fish and Wildlife Service. In: Green, T.R.T.a.C.C. (Ed.), Cryopreservation in Aquatic Species, 2nd Ed. World Aquaculture Society, Baton Rouge, Louisiana, pp. 780782.

WHO, 2010. WHO laboratory manual for the Examination and processing of human semen, 5th ed. World Health Organization, Geneva. 
Williot, P., Rochard, E., Desse-Berset, N., Kirschbaum, F., Gessner, J. (Eds.), 2011. Biology and conservation of the European sturgeon Acipenser sturio L. 1758: the reunion of the European and Atlantic sturgeons. Springer-Verlag Berlin Heidelberg. doi:10.1007/978-3-642-20611-5.

Wolf, K., Quimby, M.C., 1969. Fish cell and tissue culture, in: W.S. Hoar, D.J. Randall (Eds.), Fish Physiology Vol. III. Academic Press, New York, 253-305.

Woods, S.A., Rhodes, L., Adams, S.L., Adamson, J.E., Smith, K.F., Smith, J.F., Tervit, H.R., Cary, S.C., 2008. Maintenance of cyanotoxin by cryopreserved cyanobacteria in the New Zealand culture collection. New Zeal. J. Mar. Fresh. 42, 277-283.

Yan, S.Y., Lu, D.Y., Du, M., Li, G.S., Han, Z., Yang, H.Y., Wu, Z.G., Yang, Y.Q., Xia, D.Q., Liu, A.Z., Zhang, X.Z., 1985. Nuclear transplantation in teleosts. IVA. Nuclear transplantation between different subfamilies-hybrid fish from the nucleus of grass carp (Ctenopharyngodon idellas) and the cytoplasm of bluntsnout bream (Megalobrama amblycephala). Chinese J. Biotech. 1, 15-26.

Yang, H., Tiersch, T.R., 2009. Current status of sperm cryopreservation in biomedical research fish models: Zebrafish, medaka, and Xiphophorus. Comp. Biochem. Phys. C. $149,224-232$.

Yang, H., Carmichael, C., Varga, Z.M., Tiersch, T.R., 2007a. Development of a simplified and standardized protocol with potential for high-throughput for sperm cryopreservation in zebrafish Danio rerio. Theriogenology. 68, 128-136.

Yang, H., Hazlewood, L., Walter, R.B., Tiersch, T.R., 2009. Sperm cryopreservation of a live-bearing fish, Xiphophorus couchianus: Male-to-male variation in postthaw motility and production of F1 hybrid offspring. Comp. Biochem. Phys. C. 149, 233-239. 
Yang, H., Norris, M., Winn, R., Tiersch, T.R., 2010. Evaluation of cryoprotectant and cooling rate for sperm cryopreservation in the euryhaline fish medaka Oryzias latipes. Cryobiology. 61, 211-219.

Yang, H., Hazlewood, L., Heater, S.J., Guerrero, P.A., Walter, R.B., Tiersch, T.R., 2007b. Production of F1 interspecies hybrid offspring with cryopreserved sperm from a live-bearing fish, the swordtail Xiphophorus helleri. Biol. Reprod. 76, 401-406.

Yasui, G.S., Fujimoto, T., Sakao, S., Yamaha, E., Arai, K., 2011. Production of loach (Misgurnus anguillicaudatus) germ-line chimera using transplantation of primordial germ cells isolated from cryopreserved blastomeres. J. Anim. Sci. 89, $2380-2388$.

Yildiz, C., Yavas, I., Bozkurt, Y., Aksoy, M., 2015. Effect of cholesterol-loaded cyclodextrin on cryosurvival and fertility of cryopreserved carp (Cyprinus carpio) sperm. Cryobiology. 70, 190-194.

Yoshizaki, G., Fujinuma, K., Iwasaki, Y., Okutsu, T., Shikina, S., Yazawa, R., Takeuchi, Y., 2011. Spermatogonial transplantation in fish: A novel method for the preservation of genetic resources. Comp. Biochem. Phys. D. 6, 55-61.

Zhang, Q.-J., Zhou, G.-B., Wang, Y.-P., Fu, X.-W., Zhu, S.-E., 2012. Cryoprotectants protect medaka (Oryzias latipes) embryos from chilling injury. Cryoletters. 33, 107-116.

Zhang, T., Rawson, D.M., 1995. Studies on chilling sensitivity of zebrafish (Brachydanio rerio) embryos. Cryobiology. 32, 239-246.

Zhang, T., Rawson, D.M., 1998. Permeability of dechorionated one-cell and six-somite stage zebrafish (Brachydanio rerio) embryos to water and methanol.

Cryobiology. 37, 13-21. 
Zhang, T., Liu, X.-H., Rawson, D.M., 2003. Effects of methanol and developmental arrest on chilling injury in zebrafish (Danio rerio) embryos. Theriogenology. 59, 1545-1556.

Zhang, T., Isayeva, A., Adams, S.L., Rawson, D.M., 2005a. Studies on membrane permeability of zebrafish (Danio rerio) oocytes in the presence of different cryoprotectants. Cryobiology. 50, 285-293.

Zhang, T., Wang, R.Y., Bao, Q.-Y., Rawson, D.M., 2006. Development of a new rapid measurement technique for fish embryo membrane permeability studies using impedance spectroscopy. Theriogenology. 66, 982-988.

Zhang, T., Rawson, D., Pekarsky, I., Blais, I., Lubzens, E., 2007. Low-temperature preservation of fish gonad cells and oocytes. In: Babin, P., Cerdà, J., Lubzens, E. (Eds.), The Fish Oocyte. Springer Netherlands, pp. 411-436.

Zhang, Y.Z., Zhang, S.C., Liu, X.Z., Xu, Y.J., Hu, J.H., Xu, Y.Y., Li, J., Chen, S.L., 2005b. Toxicity and protective efficiency of cryoprotectants to flounder (Paralichthys olivaceus) embryos. Theriogenology. 63, 763-773.

Zilli, L., Vilella, S., 2012. Effect of cryopreservation on bio-chemical parameters, DNA integrity, protein profile and phosphorylation state of proteins of seawater fish spermatozoa In: Katkov, I. (Ed.), Current Frontiers in Cryobiology. InTech, Croacia, pp. 391-414.

Figure 1. Publications dedicated to cryopreservation of sperm from diferent fish species in the last 5 years (source: sciencedirect). 
Figure 2. Type of cryopreservation research done in the last five years (source: sciencedirect).

Figure 3. Publications dedicated to sperm cryopreservation from marine species $v s$ freshwater species (source: sciencedirect).

Figure 4. Distribution of publications dealing with embryo cryopreservation in relation with invertebrate species.

Table 1. Steps involved in large-scale repository of model species or of any other species (Tiersch et al., 2011).

Table 2. Studies performed in embryo resistance to chilling and cryopreservation over the last years.

Table 3. Summary of the main cryobanks in Europe. 


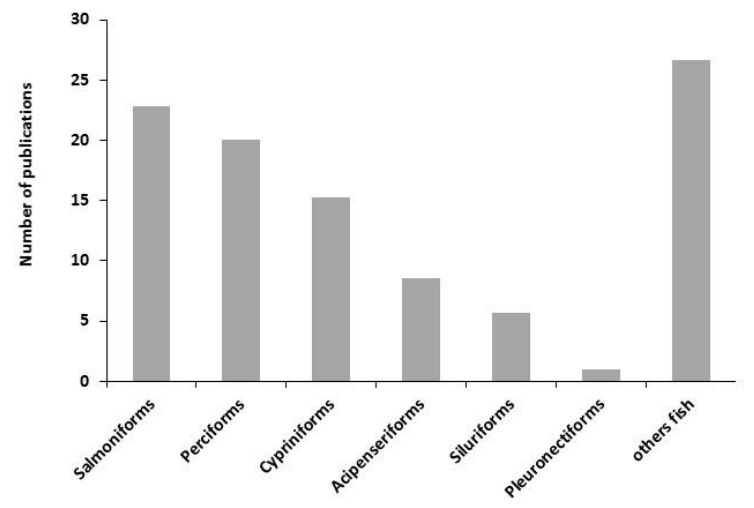

Figure 1 


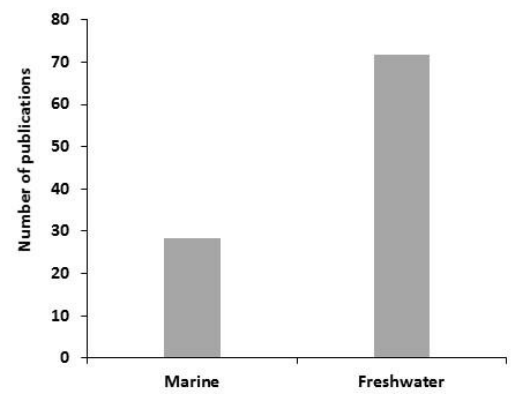

Figure 2 


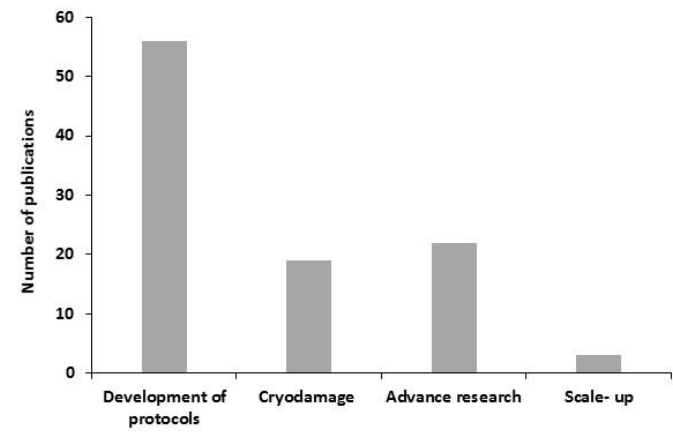

Figure 3 




Figure 4 
Table 1

\begin{tabular}{|c|c|}
\hline Action & Purpose \\
\hline $\begin{array}{l}\text { Development of the technical capabilities, } \\
\text { and establishment of standardized and } \\
\text { streamlined procedures. } \\
\text { Development of equipment, devices and } \\
\text { facilities. }\end{array}$ & $\begin{array}{l}\text { High-throughput processing and reliable } \\
\text { quality control of samples. } \\
\begin{array}{l}\text { Automated handling of small sample } \\
\text { volumes. }\end{array}\end{array}$ \\
\hline $\begin{array}{l}\text { Establishment of quality control protocols } \\
\text { and standardization or harmonization of } \\
\text { protocols, labelling, terminology and } \\
\text { reporting of results. }\end{array}$ & $\begin{array}{l}\text { Establish databases, development of best } \\
\text { practices manuals or other guidelines. } \\
\text { Develop cooperation with other } \\
\text { organizations and facilities. These }\end{array}$ \\
\hline $\begin{array}{l}\text { Development of central facilities } \\
\text { strong operational capabilities. }\end{array}$ & $\begin{array}{l}\text { relationships can include sharing of samples, } \\
\text { capabilities and expertise. } \\
\text { Education of personnel from different user } \\
\text { laboratories for procedural efficiency. }\end{array}$ \\
\hline $\begin{array}{l}\text { Development of } \\
\text { safeguards. }\end{array}$ & $\begin{array}{l}\text { Control movement of pathogens in and out } \\
\text { of facilities and other adverse biological } \\
\text { effects. }\end{array}$ \\
\hline $\begin{array}{l}\text { Development of functioning storage re } \\
\text { positories. }\end{array}$ & $\begin{array}{l}\text { Provide rules for use and disposal of samples } \\
\text { with appropriate security and backup for } \\
\text { basic services. }\end{array}$ \\
\hline $\begin{array}{l}\text { Implementation of archival-quality labelling } \\
\text { and creation of robust databases. }\end{array}$ & $\begin{array}{l}\text { Handling biological information and } \\
\text { maintaining inventory and identification of } \\
\text { sample locations. }\end{array}$ \\
\hline Integration of sperm & $\begin{array}{l}\text { Exchange information with existing databases } \\
\text { for biological and genetic information of } \\
\text { strains or lines. }\end{array}$ \\
\hline
\end{tabular}




\section{Table 2}

\begin{tabular}{|c|c|c|c|}
\hline Scientific name & Common name & Marine/Fres & References \\
\hline Seophtholmus moximus & turbot & marine & Cabrita et al., 2003; Robles etal., 2003b \\
\hline Porolichthys olivoceus & oliveflounder & marine & $\begin{array}{l}\text { Chen and Tian 2005; Edashige et al., } \\
\text { 2006; Zhang etal., 2005b }\end{array}$ \\
\hline Pogrus major & red sea bream & marine & Ding etal., 2007 \\
\hline Sillogo joponico & Japanese sillago & marine & Rahman et al., 2011 \\
\hline Sporus ouroto & gilthead seabream & marine & Robles et al., 2007 \\
\hline $\begin{array}{l}\text { Pseudopleuroneetes } \\
\text { omericonus }\end{array}$ & winter flounder & marine & Robles et al., 2005 \\
\hline Lobeo rohito & Indian carp & freshwater & Ahammad etal., 2003 \\
\hline Cyprinus corpio & common carp & freshwater & Dinnyes etal., 1998 \\
\hline Tinea tinea & tench & freshwater & El-Battawy and Linhart2009 \\
\hline Rhinelepis ospero & acarf & freshwater & Fornari et al., 2014 \\
\hline Pioroctus mesopotomicus & pacu & freshwater & Neves etal., 2014 \\
\hline Pioroetus broehypomus & pacu bianco & freshwater & Pessoa et al., 2014 \\
\hline Oryzios lotipes & medaka & freshwater & Valdez et al., 2005; Zhang et al., 2012 \\
\hline Misgurnus onguillieoudotus & oriental weatherfish & freshwater & Yasui et al., 2011 \\
\hline Donio rerio & zebrafish & freshwater & $\begin{array}{l}\text { Desai et al., 2011; Lahnsteiner 2008; Liu } \\
\text { ot } \\
\text { al., 2001b; Martfnez-Paramo et al., } \\
\text { 2009a; Robles et al., } 2004\end{array}$ \\
\hline
\end{tabular}


Table 3

\begin{tabular}{|c|c|c|c|c|c|c|}
\hline $\begin{array}{l}\text { Name } \\
\text { (country }\end{array}$ & Purpose & Species & $\begin{array}{l}\text { Type of } \\
\text { frozen } \\
\text { collecti }\end{array}$ & Specificity & $\begin{array}{l}\text { Costs } \\
\text { coverage }\end{array}$ & Internet site or contact \\
\hline $\begin{array}{l}\text { Cryoban } \\
k \text { of the } \\
\text { National } \\
\text { Academ } \\
y \text { of } \\
\text { Science } \\
\text { (Ukraine }\end{array}$ & $\begin{array}{l}\text { Conservati } \\
\text { on } \\
\text { Restoratio } \\
\mathrm{n} \\
\text { Breeders }\end{array}$ & $\begin{array}{l}\text { Wild fish: } \\
\text { Carps, } \\
\text { trouts } \\
\text { sturgeons } \\
\text {, many } \\
\text { rare } \\
\text { species }\end{array}$ & $\begin{array}{l}\text { on } \\
\text { sperm }\end{array}$ & $\begin{array}{l}\text { First fish } \\
\text { sperm bank } \\
\text { in Europe, } \\
\text { sperm from } \\
\text { extinct lines }\end{array}$ & $\begin{array}{l}\text { Puh lie } \\
\text { funding }\end{array}$ & $\begin{array}{l}\text { ekooeik@vahoo.com (Dr } \\
\text { Evgeniy Kopeika) }\end{array}$ \\
\hline $\begin{array}{l}\text { '́rozen } \\
\text { Ark (UK) }\end{array}$ & $\begin{array}{l}\text { Conservati } \\
\text { on }\end{array}$ & $\begin{array}{l}\text { Wild fish } \\
\text { from } 112 \\
\text { UK } \\
\text { species }\end{array}$ & $\begin{array}{l}\text { Tissues, } \\
\text { DNA, } \\
\text { cells, } \\
\text { blood }\end{array}$ & $\begin{array}{l}\text { Preservation } \\
\text { of biological } \\
\text { know ledge }\end{array}$ & $\begin{array}{l}\text { Pub lie } \\
\text { funding } \\
\text { (Consortium } \\
\text { ) }\end{array}$ & ww.frozenark.ors \\
\hline $\begin{array}{l}\text { Crvo- } \\
\text { Brehm } \\
\text { (fierman } \\
\text { y) }\end{array}$ & $\begin{array}{l}\text { Conservati } \\
\text { on } \\
\text { Research }\end{array}$ & $\begin{array}{l}\text { All wild } \\
\text { animals, } \\
\text { morethan } \\
20 \\
\text { fishspecie } \\
\mathrm{s}\end{array}$ & $\begin{array}{l}\text { Tissues, } \\
\text { DNA, } \\
\text { cells, } \\
\text { cell } \\
\text { lines, } \\
\text { blood } \\
\text { (sperm) }\end{array}$ & $\begin{array}{l}\text { Member } \\
\text { ofthe Frozen } \\
\text { Ark } \\
\text { consortium } \\
\text { Cell line } \\
\text { provider for } \\
\text { research }\end{array}$ & $\begin{array}{l}\text { Pub lie } \\
\text { funding } \\
\text { (Franhofer } \\
\text { Inst.) }\end{array}$ & $\begin{array}{l}\text { www.crvobrehm.de } \\
\text { phillip.ciba@emb.fraunhof } \\
\text { er.de }\end{array}$ \\
\hline $\begin{array}{l}\text { RIFCH } \\
\text { Bank } \\
\text { (Czech } \\
\text { Republic } \\
\text { ) }\end{array}$ & $\begin{array}{l}\text { Conservati } \\
\text { on } \\
\text { Breeders }\end{array}$ & $\begin{array}{l}\text { Farmed f } \\
\text { ish: } \\
7 \mathrm{FW} \\
\text { species, } \\
\text { including }\end{array}$ & Sperm & $\begin{array}{l}\text { Part of } \\
\text { National } \\
\text { Program for } \\
\text { Conservatio } \\
\mathrm{n} \text { of FAGR }\end{array}$ & $\begin{array}{l}\text { Puh lie } \\
\text { funding }\end{array}$ & $\begin{array}{l}\text { flaishans@frov.icu.cz (Prof } \\
\text { Ing Martin Flcjshans) }\end{array}$ \\
\hline $\begin{array}{l}\text { rryoAqu } \\
\text { a } \\
\text { (France) }\end{array}$ & $\begin{array}{l}\text { rnnservati } \\
\text { on } \\
\text { Breeders }\end{array}$ & $\begin{array}{l}\text { Farmed } \\
\text { resources } \\
\text { : Trout, } \\
\text { oyster }\end{array}$ & Sperm & $\begin{array}{l}\text { Both private } \\
\text { storage/Fre } \\
\text { nch National } \\
\text { Cryobank } \\
\text { (CRB-Anim) }\end{array}$ & $\begin{array}{l}\text { Fees } \\
\text { (private } \\
\text { storage)/Pu } \\
\text { blic funding } \\
\text { (conservatio } \\
\text { n) }\end{array}$ & $\begin{array}{l}\text { labcoroduction35@evolution- } \\
\text { *III/ } \\
\text { www.crvobanaue.ors } \\
\text { www.crb-anim.fr } \\
\text { clabbe@rennesinra.fr }\end{array}$ \\
\hline $\begin{array}{l}\text { EZRC } \\
\text { (German } \\
\text { y) }\end{array}$ & $\begin{array}{l}\text { Recearch } \\
\text { (EU) }\end{array}$ & Zebrafish & Sperm & $\begin{array}{l}\text { Transgenic } \\
\text { lines } \\
\text { nrovider }\end{array}$ & $\begin{array}{l}\text { Fee to get } \\
\text { back the line }\end{array}$ & www.ezrc.kıt.edu \\
\hline
\end{tabular}

